\title{
A fully coupled air foil bearing model considering friction - Theory \& experiment
}

\author{
von Osmanski, Alexander Sebastian; Larsen, Jon Steffen; Santos, IImar
}

Published in:

Journal of Sound and Vibration

Link to article, DOI:

10.1016/j.jsv.2017.04.008

Publication date:

2017

Document Version

Peer reviewed version

Link back to DTU Orbit

Citation (APA):

von Osmanski, A. S., Larsen, J. S., \& Santos, I. (2017). A fully coupled air foil bearing model considering friction - Theory \& experiment. Journal of Sound and Vibration, 400, 660-679. https://doi.org/10.1016/j.jsv.2017.04.008

\section{General rights}

Copyright and moral rights for the publications made accessible in the public portal are retained by the authors and/or other copyright owners and it is a condition of accessing publications that users recognise and abide by the legal requirements associated with these rights.

- Users may download and print one copy of any publication from the public portal for the purpose of private study or research.

- You may not further distribute the material or use it for any profit-making activity or commercial gain

- You may freely distribute the URL identifying the publication in the public portal 


\title{
A fully coupled air foil bearing model considering friction - Theory \& experiment
}

\author{
Sebastian von Osmanski ${ }^{\mathrm{a}}$, Jon S. Larsen ${ }^{\mathrm{a}}$, Ilmar F. Santos ${ }^{\mathrm{a}}$ \\ ${ }^{a}$ Department of Mechanical Engineering, Technical University of Denmark, 2800 Kgs. Lyngby, Denmark
}

\begin{abstract}
The dynamics of air foil bearings (AFBs) are not yet fully captured by any model. The recent years have, however, seen promising results from nonlinear time domain models, and simultaneously coupled formulations are now available, avoiding the previous requirements for undesirably small time steps and temporal convergence studies.

In the present work, an alternative foil structure model is substituted for the simple elastic foundation model to avoid its inherent limitations. The new foil model is based on a truss representation from the literature, but incorporates the foil mass and a dynamic friction model. As a consequence of the friction model's velocity dependency, the foil mass is included to obtain a set of differential equations that can be coupled to the rotor and fluid domains while allowing a simultaneous solution.

Considerations leading to a practically applicable implementation are discussed and numerical results are compared with experimental data. The model predicts natural frequencies and mode shapes well, but it is not yet capturing the unbalance response when friction is considered. Possible causes for this discrepancy are discussed and it is suggested that sticking is a more prevalent state than previously assumed.
\end{abstract}

Keywords:

Air foil bearing, rigid rotor, transient simulation, nonlinear analysis, friction

\section{Nomenclature}

$\begin{array}{ll}\text { AFB } & \text { Air Foil Bearing } \\ \text { CG } & \text { Center of Gravity } \\ \text { DAE } & \text { Differential/Algebraic Equation } \\ \text { EOM } & \text { Equation of Motion } \\ \text { FD } & \text { Finite Difference } \\ \text { FE } & \text { Finite Element } \\ \text { FRF } & \text { Frequency Response Function } \\ \text { LOM } & \text { Light Optical Microscopy } \\ \text { ODE } & \text { Ordinary Differential Equation } \\ \text { PDE } & \text { Partial Differential Equation } \\ \text { RE } & \text { Reynolds Equation } \\ \text { SEFM } & \text { Simple Elastic Foundation Model } \\ \text { DOF } & \text { Degree of Freedom } \\ \left.()^{*}\right) & \text { Time derivative, } d^{2} / d \tau^{2} \\ ()^{*} & \text { Time derivative, } d / d \tau \\ ()^{e} & \text { Element specific } \\ (\sim) & \text { Nondimensional quantity }\end{array}$

$\begin{array}{ll}\nabla \cdot & \text { Divergence } \\ \nabla & \text { Gradient, } \nabla=\{\partial / \partial \theta, \partial / \partial \tilde{z}\} \\ A, B & \text { Bearings } \\ a & \text { Scalar field quantity } \\ C & \text { Radial clearance } \\ E_{b} & \text { Young's modulus of bump foil material } \\ E_{t} & \text { Young's modulus of top foil material } \\ e, \varepsilon & \text { Journal eccentricity components, } \varepsilon=e / C \\ F, \tilde{F} & \text { Bearing force components, } \tilde{F}=1 /\left(p_{a} R^{2}\right) F \\ f_{\mu} & \text { Friction force } \\ f_{N} & \text { Normal force } \\ h, \tilde{h} & \text { Film height, } \tilde{h}=h / C \\ h_{b} & \text { Bump foil height } \\ h_{c}, \tilde{h}_{c} & \text { Film height (compliant), } \tilde{h}_{c}=h_{c} / C \\ h_{r}, \tilde{h}_{r} & \text { Film height (rigid), } \tilde{h}_{r}=h_{r} / C \\ h_{s}, \tilde{h}_{s} & \text { Slope height, } \tilde{h}_{s}=h_{s} / C \\ I & \text { Mass moment of inertia }\end{array}$

Email addresses: asvosm@mek.dtu.dk (Sebastian von Osmanski), josla@mek.dtu.dk (Jon S. Larsen), ifs@mek.dtu.dk (Ilmar F. Santos) 
$I_{t} \quad$ Top foil area moment of inertia

$k_{b} \quad$ Structural bump stiffness per unit area

$k_{j}, d_{j} \quad$ Truss stiffness and damping, $j \in\{1,1 b, 2,3,3 b, 4\}$

$k_{t} \quad$ Asperity stiffness

$L, \tilde{L} \quad$ Bearing length, $\tilde{L}=L / R$

$l_{0} \quad$ Bump half length

$l_{1}, l_{2} \quad$ Distance from CG to bearings

$l_{3}, l_{4} \quad$ Distance from CG to discs

$l_{t} \quad$ Top foil length

$m \quad$ Mass

$m_{b} \quad$ Bump foil mass per bump

$N_{b} \quad$ Number of bumps

$N_{p} \quad$ Number of bearing pads

$p, \tilde{p} \quad$ Film pressure, $\tilde{p}=p / p_{a}$

$p_{1}^{e}, p_{2}^{e} \quad$ Pressure values at nodes

$p_{a} \quad$ Ambient pressure

$\tilde{p}_{m} \quad$ Nondimensional mean axial pressure

$R \quad$ Journal radius

$R_{b} \quad$ Bump radius of curvature

$S \quad$ Compressibility number, $S=6 \mu \omega / p_{a}(R / C)^{2}$

$S_{b} \quad$ Bump foil pitch

$t \quad$ Physical time

$t_{b} \quad$ Thickness of bump foil

$t_{t} \quad$ Thickness of top foil

$U \quad$ Unbalance $\mathrm{kg} \cdot \mathrm{m}$

$v_{r} \quad$ Relative sliding velocity

$W, \tilde{W} \quad$ Static load components, $\tilde{W}=1 /\left(p_{a} R^{2}\right) W$

$x, y, z, \tilde{z}$ Cartesian coordinates, $\tilde{z}=z / R$

$x_{r} \quad$ Relative displacement

$\alpha \quad$ Bearing position

$\gamma \quad$ Friction function smoothing parameter

$\mu \quad$ Dynamic viscosity

$\mu_{f} \quad$ Coefficient of friction

$v_{b} \quad$ Poisson's ratio of bump foil material

$v_{t} \quad$ Poisson's ratio of top foil material

$\omega \quad$ Angular speed of journal

$\Phi \quad$ Fluid domain

$\psi \quad$ Film state variable (nondimensional), $\psi=\tilde{p} \tilde{h}$

$\rho_{t} \quad$ Density of top foil material

$\rho_{b} \quad$ Density of bump foil material

$\tau \quad$ Dimensionless time, $\tau=\omega t$

$\theta \quad$ Circumferential angle

$\theta^{\prime} \quad$ Curvelinear coordinate, $\theta^{\prime}=\theta R$

$\tilde{\theta}$ Dimensionless circumferential coordinate, $\tilde{\theta}=\theta^{\prime} / R=\theta$

$\theta_{0} \quad$ Bump half angle

$\theta_{i} \quad$ Inlet slope end angle for $i$-th pad

$\theta_{j} \quad$ Truss transmission angle, $\theta_{d}$ or $\theta_{d b}$

$\theta_{l} \quad$ First pad leading edge angle

$\theta_{l i} \quad$ Leading edge angle for $i$-th pad

$\theta_{s} \quad$ Inlet slope extend

$\theta_{t} \quad$ First pad trailing edge angle

$\theta_{t i} \quad$ Trailing edge angle for $i$-th pad

$\xi_{i}, \eta_{j} \quad$ Gauss points

$\zeta \quad$ Damping ratio

$\mathbf{a}^{e} \quad$ Vector of field quantities at element nodes

$\boldsymbol{\varepsilon} \quad$ Eccentricity vector

$\mathbf{f}, \tilde{\mathbf{f}} \quad$ Bearing force vector, $\mathbf{f}=\left\{\mathbf{f}_{A}^{T}, \mathbf{f}_{B}^{T}\right\}^{T}, \tilde{\mathbf{f}}=1 /\left(p_{a} R^{2}\right) \mathbf{f}$

$\mathbf{f}_{\mu} \quad$ Vector of friction forces

$\mathbf{f}_{p} \quad$ Vector of pressure forces

$\mathbf{f}_{u b}, \tilde{\mathbf{f}}_{u b} \quad$ Unbalance force, $\tilde{\mathbf{f}}_{u b}=1 /\left(p_{a} R^{2}\right) \mathbf{f}_{u b}$

g() Nonlinear vector function

$\tilde{\mathbf{h}}_{c} \quad$ Foil deformation vector

$\tilde{\mathbf{p}} \quad$ Pressure vector

$\psi \quad$ Film state vector

r Residual vector

s Advection vector, $\mathbf{s}=\{S, 0\}^{T}$

$\tilde{\mathbf{u}} \quad$ Foil structure state space vector

$\mathbf{w}, \tilde{\mathbf{w}} \quad$ Load vector, $\tilde{\mathbf{w}}=1 /\left(p_{a} R^{2}\right) \mathbf{w}$

$\mathbf{x} \quad$ Foil displacement vector

y Global state vector

$\mathbf{z}_{1} \quad$ Rotor displacement vector, $\mathbf{z}_{1}=\boldsymbol{\varepsilon}$

$\mathbf{z}_{2} \quad$ Rotor velocity vector, $\mathbf{z}_{2}=\dot{\boldsymbol{\varepsilon}}$

0 Zero matrix

$\mathbf{A}_{f}, \tilde{\mathbf{A}}_{f} \quad$ Foil structure system matrix

B Shape function derivatives matrix

$\mathbf{D}_{f}, \tilde{\mathbf{D}}_{f} \quad$ Foil structure damping matrix

$\boldsymbol{\Gamma} \quad$ Fluidity matrix

$\mathbf{G}_{r}, \tilde{\mathbf{G}}_{r} \quad$ Rotor gyroscopic matrix, $\tilde{\mathbf{G}}_{r}=\omega^{2} C /\left(p_{a} R^{2}\right) \mathbf{G}_{r}$

I Identity matrix

$\mathbf{K}_{b} \quad$ Bump foil structure stiffness matrix

$\mathbf{K}_{f}, \tilde{\mathbf{K}}_{f}$ Foil structure stiffness matrix

$\mathbf{K}_{t} \quad$ Top foil structure stiffness matrix

$\mathbf{M}_{f}, \tilde{\mathbf{M}}_{f}$ Foil structure mass matrix

$\mathbf{M}_{r}, \tilde{\mathbf{M}}_{r}$ Rotor mass matrix, $\tilde{\mathbf{M}}_{r}=\omega^{2} C /\left(p_{a} R^{2}\right) \mathbf{M}_{r}$

$\mathbf{M}_{t} \quad$ Top foil mass matrix

$\mathbf{N} \quad$ Shape function matrix

\section{Introduction}

Vibrations of rotor-bearing systems have been subject to investigation at least since Rankine [1] published his findings on lateral vibrations in 1869 . Later, the mathematical description of fluid film bearings was enabled by the findings of Reynolds, [2] and the course of modern rotordynamics was charted by Jeffcott [3] in 1919. 
While the Reynolds equation (RE) was already extended to encompass compressible lubricants by Harrison [4] in 1913, the practical interest in gas lubrication can be traced back to the mid-1950s. At this point, especially two applications appeared to which gas lubrication became attractive. One was inertial navigation systems to be used during prolonged submerged operation by nuclear submarines. The second was gas pumps located inside the radioactive gas circuits of nuclear power reactors [5]. Along with advances within experimental equipment and the emergence of computerised numerical solutions, these new applications strongly facilitated the development of practical gas lubrication. During the 1960s, the first gas bearings with compliant surfaces appeared and the air foil bearing (AFB) type was first put into production by Garrret AiResearch in the late 1960s [6]. Since then, AFB technology has evolved significantly, and more recent efforts even strive towards creating a completely oil-free turbine engine using AFBs [7].

The compliant inner surface of AFBs counteracts some of the inherent issues of rigid gas bearings, such as the small tolerance to shaft growth and misalignment. Unfortunately, AFBs can also introduce undesirable nonlinear phenomena into the dynamics of a rotor-bearing system, and lateral vibrations stemming from such nonlinearities are often the limiting factor of an AFB design. Reliable means for predicting the nonlinear unbalance response are hence necessary for further spread of the technology.

Although nonlinear transient analysis of oil lubricated bearings was performed as early as 1967 [8], the majority of the gas bearing literature concerns perturbation solution methods. These apply to the frequency-domain and rely on linearisation of the reaction forces around the static equilibrium to effectively replace the bearing and fluid film with a spring-dashpot system. Some of the first to apply such methods to compliant type gas bearings were Heshmat et al. [9], who included the compliance by introducing a linear elastic function of the fluid film pressure directly into the steady compressible RE. Even though the top foil was disregarded entirely and any interaction between neighbouring points in the foil structure was neglected, it allowed the equilibrium state to be obtained while taking into account the dynamic interaction between foil compliance and fluid film pressure. This approach to introduce compliance has later been referred to as the simple elastic foundation model (SEFM), and in 1993, it was linked by Peng and Carpino [10] to the perturbation method given by Lund [11,12]. This combination has subsequently been applied directly and along with various SEFM extensions by many authors, e.g. [13-17, 17-21].

The perturbation methods are, however, inherently restricted to an assumed small-amplitude periodic motion [22], and recent work [23] additionally suggests an inadequacy in the usually applied Taylor series expansion of the pressure field. One possible way of overcoming these limitations is nonlinear time-domain integration, which is becoming increasingly practicable due to the growing computational resources available. Some of the first to present transient simulations of compliant gas bearings were Grau et al. [24], and more advanced foil structure models have been used for time-simulations by Lee et al. [25] and Le Lez et al. [26]. A primary challenge for these models is the pressure and film thickness temporal derivatives, which are approximated using finite differences (FDs). This inevitably introduces a time-lack between the variables, rendering the models non-simultaneous as stated in [27, 28]. The time-lack issue can, to some extent, be made up for by using very small time steps, but the solution will remain dependent on the step size and convergence studies are, strictly speaking, necessary [29].

Bonello and Pham $[27,28]$ solved this issue by substituting an alternative fluid state variable for the film heightpressure product. The substitution allows the unsteady compressible RE to be treated as a system of ordinary differential equations (ODEs) and hence to retain the true simultaneously coupled nature of the state variables. This approach has later been used to obtain the unbalance response of a rigid rotor supported by industrial three-pad AFBs with good agreement to experimental data $[29,30]$.

While FD and finite element (FE) spatial discretisations are used in [27, 28] and [29, 30], respectively, both rely on the SEFM incorporating a loss factor. This implies that: $(a)$ the foil structure's energy dissipation is modelled as being viscous; $(b)$ the stiffness is linear and independent of both deformation and frequency; and $(c)$ neighbouring points in the foil are assumed to deform independently. These are rather crude approximations which calls for the adoption of more realistic foil structure models.

A possible bump foil model for this purpose, which is still sufficiently simple to be suitable for time-domain simulation, is suggested by Le Lez et al. [31] based on a truss with member stiffness coefficients derived from the foil geometry. In contrast to the radially acting spring-dashpot pairs of the SEFM and its relatives, the truss model takes into account bump-bump coupling and it includes circumferential displacements facilitating the inclusion of friction.

In the present paper, the truss based bump foil model from [31] is coupled to a simple one-dimensional top foil model similar to that used in [32], the FE discretised unsteady compressible RE previously used by the authors $[23,29,30]$ and a smoothed dynamic friction model as discussed in e.g. [33-35]. Even though the foil dynamics are 
widely accepted to be negligible as argued in e.g. [36], the foil mass is furthermore included in order to retain the simultaneity of the equation system. This is important as it distinguishes the presented model from existing coupled models with friction in the literature.

The purpose of the proposed model extensions is twofold: Firstly, to increase the generality of the AFB model, and secondly, to mimic the physical mechanism for energy dissipation more closely. While the agreement to experimental data presented in [29] was already notable, this was achieved through a careful choice of foil stiffness and viscous dissipation coefficient based on a separate FE bump foil model and a number of "engineering assumptions". The truss based foil model, on the contrary, is based on directly measurable geometrical quantities and relies on much fewer assumptions.

It should be noted that while the parameters and results in the following are reported using SI-units, any consistent system could have been applied as the mathematical model and its numerical implementation rely on dimensionless quantities, marked with " $"$ ", only.

\section{Modelling of the Rigid Rotor}

The modelled test rig has previously been presented by the authors [37] and comprises a hollow shaft supported by two identical three-pad AFBs as illustrated in Fig. 1. The shaft is mounted with plane discs at its extremities to which unbalance mass can be added. The operational range of the rig is 15 to $30 \mathrm{kRPM}$ and the lowest free-free natural frequency of the assembled shaft is found to be approximately $1050 \mathrm{~Hz}$, hence a rigid shaft model is deemed adequate. The resulting four degrees of freedom (DOFs) are expressed by the nodal position vector holding the instantaneous position of the shaft at the bearing locations $A, B$ as

$$
\boldsymbol{\varepsilon}=\left\{\varepsilon_{A x}, \varepsilon_{A y}, \varepsilon_{B x}, \varepsilon_{B y}\right\}^{T} .
$$

Using Eq. (1) and under the assumption of small amplitude vibrations in the $x$ - and $y$-directions, the equation of motion (EOM) can be written in dimensionless form as the system of second order ODEs

$$
\tilde{\mathbf{M}}_{r} \ddot{\boldsymbol{\varepsilon}}-\tilde{\mathbf{G}}_{r} \dot{\boldsymbol{\varepsilon}}=\tilde{\mathbf{w}}-\tilde{\mathbf{f}}+\tilde{\mathbf{f}}_{u b},
$$
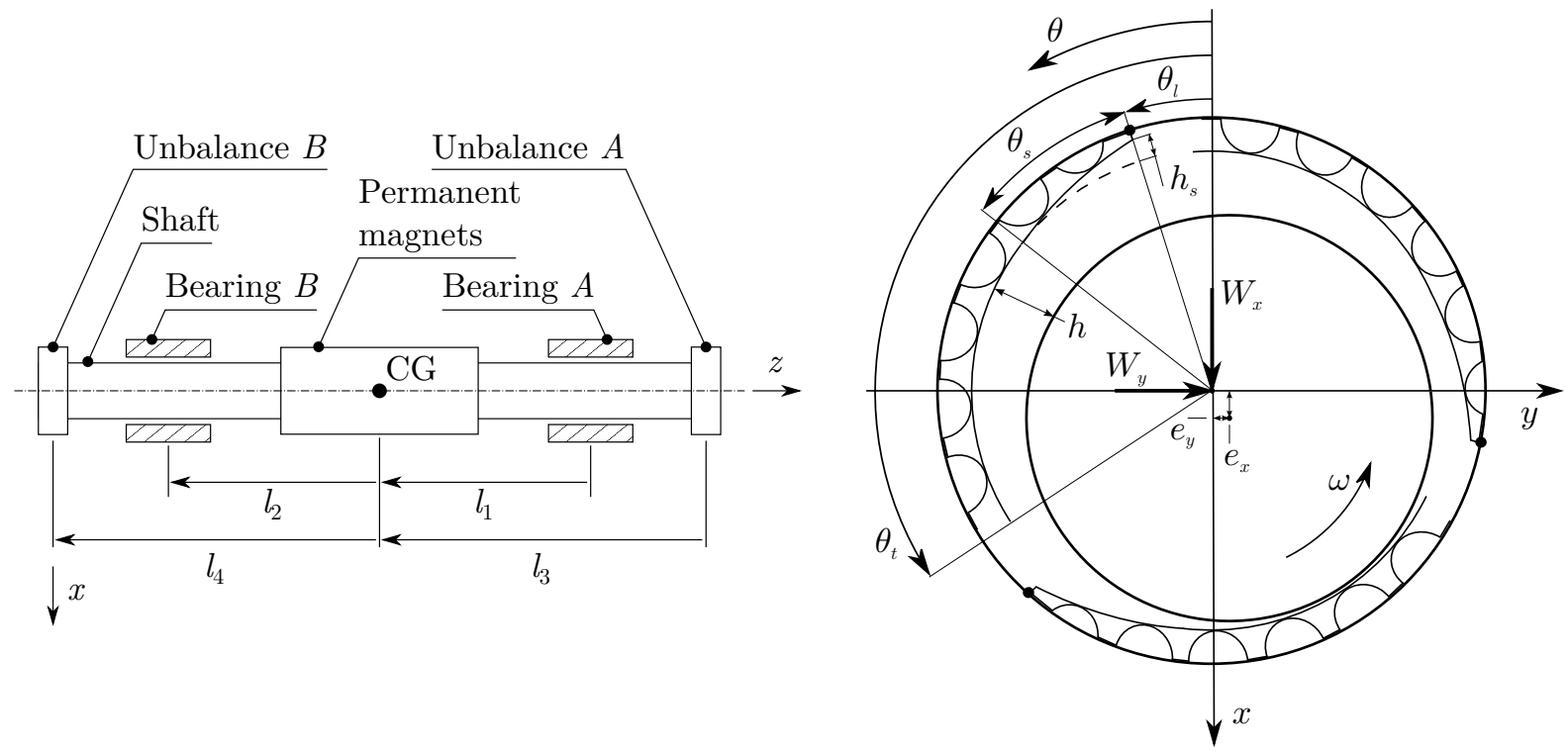

(a)

(b)

Figure 1: Schematics and nomenclature of a rigid rotor supported by foil journal bearings: (a) Shaft, bearings and rotor disks for unbalance masses; and (b) detailed view of bearing geometry. 
where $\tilde{\mathbf{M}}_{r}$ and $\tilde{\mathbf{G}}_{r}$ denote the dimensionless mass and gyroscopic matrices of the rotor, respectively, and $\tilde{\mathbf{f}}_{u b}$ is the vector of unbalance forces given in Appendix A. The static load contribution is contained in $\tilde{\mathbf{w}}$, and $\tilde{\mathbf{f}}=\left\{\tilde{\mathbf{f}}_{A}^{T}, \tilde{\mathbf{f}}_{B}^{T}\right\}^{T}$ is the reaction force vector from the bearings. The latter is given by integration of the fluid film pressure $\tilde{p}$ in each bearing $\alpha=A, B$ as

$$
\tilde{\mathbf{f}}_{\alpha}=\left\{\begin{array}{c}
\tilde{F}_{x} \\
\tilde{F}_{y}
\end{array}\right\}=\int_{0}^{\tilde{L}} \int_{0}^{2 \pi}(\tilde{p}-1)\left\{\begin{array}{c}
\cos (\theta) \\
\sin (\theta)
\end{array}\right\} d \tilde{\theta} d \tilde{z}
$$

where $\tilde{L}=L / R$ is the dimensionless bearing length and $\tilde{\theta}=\theta^{\prime} / R=\theta, \tilde{z}=z / R$ are the dimensionless circumferential and axial coordinates, respectively.

Furthermore, introducing the rotor state space vectors $\mathbf{z}_{1}=\boldsymbol{\varepsilon}$ and $\mathbf{z}_{2}=\dot{\boldsymbol{\varepsilon}}$, Eq. (2) can be recast into first order form as

$$
\left\{\begin{array}{l}
\dot{\mathbf{z}}_{1} \\
\dot{\mathbf{z}}_{2}
\end{array}\right\}=\left[\begin{array}{lc}
\mathbf{0} & \mathbf{I} \\
\mathbf{0} & \tilde{\mathbf{M}}_{r}^{-1} \tilde{\mathbf{G}}_{r}
\end{array}\right]\left\{\begin{array}{l}
\mathbf{z}_{1} \\
\mathbf{z}_{2}
\end{array}\right\}+\left\{\begin{array}{c}
\mathbf{0} \\
\tilde{\mathbf{M}}_{r}^{-1}\left(\tilde{\mathbf{w}}-\tilde{\mathbf{f}}+\tilde{\mathbf{f}}_{u b}\right)
\end{array}\right\} .
$$

\section{Modelling of the Fluid Film}

The pressure in each bearing can be obtained by solving the unsteady isothermal Reynolds equation for compressible fluids. This is a partial differential equation (PDE) nonlinear in the pressure which can be written in dimensionless vector form [38] as

$$
\nabla \cdot\left(\tilde{p} \tilde{h}^{3} \nabla \tilde{p}\right)=\nabla \cdot(\tilde{p} \tilde{h}) \mathbf{s}+2 S \frac{d}{d \tau}(\tilde{p} \tilde{h})
$$

where $S=6 \mu \omega / p_{a}(R / C)^{2}$ is the compressibility number, $\mathbf{s}=\{S, 0\}^{T}$ is the advection vector and the film height $\tilde{h}$ is divided into a rigid and a compliant contribution as first suggested by Heshmat et al. [9]:

$$
\tilde{h}=\tilde{h}_{r}\left(\varepsilon_{x}, \varepsilon_{y}, \tilde{\theta}\right)+\tilde{h}_{c} .
$$

The film height in the undeformed bearing $\tilde{h}_{r}$ depends on the rotor eccentricity components $\varepsilon_{x}, \varepsilon_{y}$ and the circumferential coordinate $\tilde{\theta}$. For a segmented bearing with inlet slopes and the nomenclature as illustrated in Fig. $1 \mathrm{~b}$, the film height contribution $\tilde{h}_{r}$ can be written as

$$
\tilde{h}_{r}\left(\varepsilon_{x}, \varepsilon_{y}, \tilde{\theta}\right)=\left\{\begin{array}{ll}
1+\varepsilon_{x} \cos (\theta)+\varepsilon_{y} \sin (\theta)-\tilde{h}_{s}\left(\frac{\theta-\theta_{i}}{\theta_{s}}\right)^{3}, & \theta_{l i} \leq \theta \leq \theta_{i} \\
1+\varepsilon_{x} \cos (\theta)+\varepsilon_{y} \sin (\theta), & \theta_{i}<\theta \leq \theta_{t i}
\end{array},\right.
$$

where the leading, inlet region and trailing edge angles of the $i$-th pad in a bearing with $N_{p}$ pads are

$$
\theta_{l i}=\theta_{l}+\frac{2 \pi}{N_{p}}(i-1), \quad \theta_{i}=\theta_{s}+\theta_{l}+\frac{2 \pi}{N_{p}}(i-1) \quad \text { and } \quad \theta_{t i}=\theta_{t}+\frac{2 \pi}{N_{p}}(i-1) .
$$

Notice from Eq. (7) that a cubic inlet slope function is used in order to mimic beam bending and hence to make $\partial^{2} \tilde{h}_{r} / \partial \tilde{\theta}^{2}$ continuous at $\theta=\theta_{i}$. This property is desirable as Eq. (5) contains second order spatial derivatives of $\tilde{h}$.

The compliant height term of Eq. (6) could be supplied by a variety of foil structure models with varying dependencies. As it will be shown in section 4 , the foil model introduced in the present work results in a $\tilde{h}_{c}$ function depending on the applied pressures and the state variables from the entire pad. This is a fundamental difference from the strictly pointwise dependency assumed in the SEFM and aims to reflect the continuous nature of the physical foil structure.

\subsection{Discretisation of Reynolds Equation}

The spatial discretisation of the fluid film PDE Eq. (5), and hence the conversion into a system of ODEs, is achieved using FE, but FD or finite volume methods could likewise have been applied. Furthermore, the alternative state variable $\psi=\tilde{p} \tilde{h}$ is introduced to maintain the simultaneity of the equation system as it was introduced in [27, 28] and subsequently used by the authors in $[23,29,30]$. 
Performing the partial substitution with $\psi$ in Eq. (5), the fluid film PDE can be expressed as

$$
\nabla \cdot\left(\tilde{p} \tilde{h}^{3} \nabla \tilde{p}\right)-\nabla \cdot(\tilde{p} \tilde{h}) \mathbf{s}-2 S \dot{\psi}=0
$$

which is then spatially discretised following a standard Bubnov-Galerkin FE procedure with implementation of an isoparametric element formulation [39]. Upon discretisation [30], this yields a system of nonlinear equations for the film state derivative vector $\psi$ on the element level

$$
\Gamma^{e} \dot{\psi}^{e}=\mathbf{r}^{e}
$$

with the fluidity matrix $\boldsymbol{\Gamma}$ and residual vector $\mathbf{r}$ given on the element level as

$$
\boldsymbol{\Gamma}^{e}=2 S \int_{\Phi^{e}} \mathbf{N}^{T} \mathbf{N} d \Phi, \quad \mathbf{r}^{e}=-\int_{\Phi^{e}} \mathbf{B}^{T} \tilde{p} \tilde{h}^{3} \mathbf{B} d \Phi \cdot \tilde{\mathbf{p}}^{e}+\int_{\Phi^{e}} \mathbf{B}^{T} \mathbf{s} \tilde{h} \mathbf{N} d \Phi \cdot \tilde{\mathbf{p}}^{e}
$$

and where $\mathbf{N}$ and $\mathbf{B}$ denote the element shape function matrix and its derivatives. The element vectors and matrices are expanded to structure size by the usual element mapping symbolised by summations [39]:

$$
\mathbf{r}=\sum_{e} \mathbf{r}^{e} ; \quad \tilde{\mathbf{p}}=\sum_{e} \tilde{\mathbf{p}}^{e} ; \quad \dot{\psi}=\sum_{e} \dot{\psi}^{e} ; \quad \boldsymbol{\Gamma}=\sum_{e} \boldsymbol{\Gamma}^{e}
$$

where the integrals are numerically integrated using a quadrature rule [39]. The scalar field quantities $\tilde{p}, \tilde{h}$ are calculated in the respective Gauss points $\left(\xi_{i}, \eta_{j}\right)$ using the interpolation functions as:

$$
a\left(\xi_{i}, \eta_{j}\right)=\mathbf{N}\left(\xi_{i}, \eta_{j}\right) \mathbf{a}^{e}
$$

where $a$ and $\mathbf{a}^{e}$ are the scalar field quantities and nodal vectors, respectively. Note that the right hand side of Eq. (10) is denoted $\mathbf{r}^{e}$, which is in fact the residual that needs to be minimised in order to find the static equilibrium of the journal. An efficient method for this minimisation is given in [16].

\subsection{Fluid Film Boundary Conditions}

Ambient pressure is enforced at the outer edges of the bearing and at the leading and trailing pad edges. This can be written in dimensionless form as

$$
\begin{aligned}
\tilde{p}(\tilde{\theta}, \tilde{L} / 2)=\tilde{p}(\tilde{\theta},-\tilde{L} / 2)=1 \\
\tilde{p}\left(\tilde{\theta}_{l i}, \tilde{z}\right)=\tilde{p}\left(\tilde{\theta}_{t i}, \tilde{z}\right)=1 \quad \text { for } \quad i=1,2, \ldots, N_{p} .
\end{aligned}
$$

The pressure $\tilde{p}$ is, however, not included explicitly in the fluid film ODEs, meaning that Eqs. (14) and (15) cannot be enforced directly. Differentiating $\psi=\tilde{p} \tilde{h}$ with respect to time, one obtains $\dot{\psi}=\dot{\tilde{p}} \tilde{h}+\tilde{p} \dot{\tilde{h}}$, from which it can be seen that $\tilde{p}=1$ corresponds to $\dot{\psi}=\dot{\tilde{h}}$, which is continuously enforced in the simulation.

As the two AFBs of the rotor-bearing test rig are assumed perfectly aligned and as the model is limited to small rotations of the shaft, the pressure profile is consequently symmetric about the bearing midplane. This is exploited to reduce the computational burden by including only one half of each bearing in the simulation. In practice, this implies that one of the edges in Eq. (14) is dropped to effectively enforce $\partial \tilde{p} / \partial \tilde{z}=0$ [30] and that the integrated fluid film reaction forces should be multiplied by two. In the process of integrating the fluid film pressures across the mesh to obtain $\tilde{\mathbf{f}}_{\alpha}$, the Gümbel condition is furthermore enforced. This means that sub-ambient pressures, i.e $\tilde{p}<1$, are discarded effectively rendering these regions inactive.

\section{Modelling of the Foil Structure}

The presented foil structure model is based on the fundamental assumption that the film height can be treated as being constant in the axial direction. This is in line with experimental results [40] and allows the foil structure to be modelled in two dimensions affected by the mean axial pressure over the bearing length $L[16,41,42]$. The three key-components of the model, namely friction, bump foil and top foil, are covered in the following sections. 


\subsection{Friction}

Energy dissipation due to sliding friction in the foil structure is widely assumed to be of major importance to the properties of AFBs, e.g. [6, 26, 32, 43], and the effective radial bump foil stiffness is strongly dependent on the stick/slip conditions at the housing contacts. Therefore, it is obvious to seek a model relying on friction to supply stiffness and damping, instead of the widely applied constant stiffness coefficients and viscous dissipation approximations.

Numerical simulation of friction is difficult due to the nonlinear behaviour of the friction force near zero velocity, and various approaches to this have been suggested. The friction models found in the literature can be roughly divided into three categories: stick-slip bookkeeping with alternating boundary conditions [25, 31, 44]; nonlinear springs with moving reference points [45]; and continuous dynamic friction force approximations [34-36, 46].

As in Coulomb's law of friction, the stick-slip bookkeeping models differentiate between static and dynamic friction regimes to apply either boundary conditions or dynamic friction forces. One such model is suggested for AFB simulation by Lee et al. [25] and relies on an algorithm for continuously evaluating the stick/slip state at each friction point. This concept is a challenge to numerical stability as non-smooth, or even discontinuous, (in time) reaction and friction forces are hardly avoidable. Also, the determination of the state transition times becomes a difficult challenge for a system with many friction interfaces, as a change of state for one friction point influences the remaining ones.

To cope with the classical issue of determining the friction force at zero velocity, Larsen et al. [45] presented an alternative model based on nonlinear springs with continuously updated reference points. The model was employed in a quasi-static framework where the times of slide direction changes were known a priori. However, it has proven difficult to apply in a dynamic framework due to the requirement of instantaneous detection of direction shifts and discontinuities in the resulting friction forces.

The third category of friction models are characterised by approximating the sign function in the Coulomb friction law using a smooth function of the relative sliding velocity $d x_{r} / d t=v_{r}$. Several approximating functions for this purpose are found in the literature, including the hyperbolic tangent, the inverse tangent and fractions similar to $v_{r} /\left|v_{r}\right|$, but with some smoothing parameter added to the denominator.

Petrov and Ewins [34] present a very interesting model based on an inverse tangent approximation taking into account also the asperity stiffness $k_{t}$. This is given as the ODE with time $t$ as the independent variable

$$
\frac{d f_{\mu}}{d t}=k_{t}\left(v_{r}-\frac{1}{\gamma} \tan \left(\frac{\pi f_{\mu}}{2 \mu_{f} f_{N}}\right)\right)
$$

where $f_{\mu}$ is the friction force, $f_{N}$ is the normal force, $\gamma$ is a smoothing parameter to the sign approximation and $\mu_{f}$ is the coefficient of friction. The treatment of friction forces as state variables is well-suited for the present purpose, but numerical difficulties have been encountered as the normal force is often close to zero in certain regions of the bearings. These issues could possibly be solved by introducing a preload as suggested in [34], but for the present, a simpler approach is taken where the friction force is given explicitly as the hyperbolic tangent approximation with the smoothing parameter $\gamma$

$$
f_{\mu}=f_{N} \mu_{f} \tanh \left(\gamma v_{r}\right) .
$$

This gives a friction force with no distinction between dynamic and static regimes, but it could be extended using a more sophisticated expression for mimicking other friction phenomena as suggested by Makkar et al. [35]. The approximation of Eq. (17) to the sign function for increasing values of $\gamma$ is illustrated in Fig. 2.

A common characteristic shared by all of the assessed friction models is velocity dependency. The stick-slip bookkeeping models require either a direct evaluation of the sliding velocity or an indirect one through comparison of positions between time steps. The mentioned nonlinear spring based model requires the velocity to be monitored in order to correctly move a reference position, and the velocity dependency of the continuous dynamic models is selfevident. To the best knowledge of the authors, no friction model exists that does not share this dependency, meaning that a simultaneously formulated AFB model including friction is not realisable without a dynamic foil structure model.

\subsection{Bump Foil Structural Model}

The bump foil is modelled as a warren-like truss with member properties derived from the foil geometry sketched in Fig. 3a. The model is illustrated for an $N_{b}=3$ bump foil strip in Fig. 4, and requires $4\left(N_{b}+1\right)$ DOFs, of which 


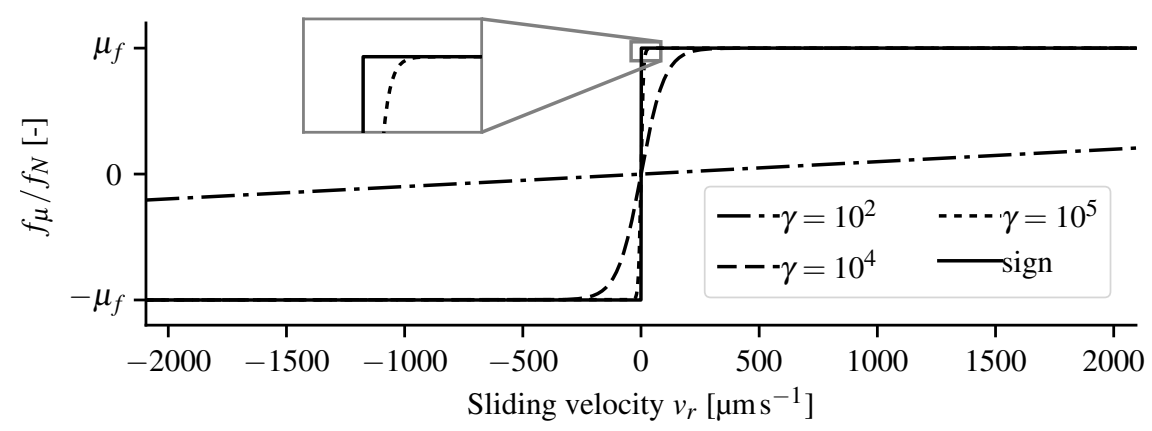

Figure 2: The $f_{\mu} / f_{N}$ ratios resulting from Eq. (17) using different values of the smoothing parameter $\gamma$ compared with the sign function. For reference, $\pm 2000 \mu \mathrm{m} \mathrm{s}^{-1}$ corresponds to the maximum velocity reached by a $0.5 \mathrm{X}$ frequency sliding motion with an amplitude of $2 \mu \mathrm{m}$ at $20 \mathrm{kRPM}$.

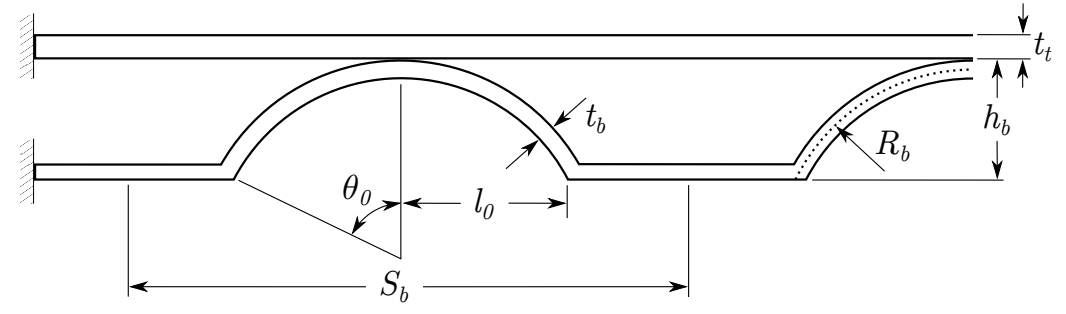

(a)

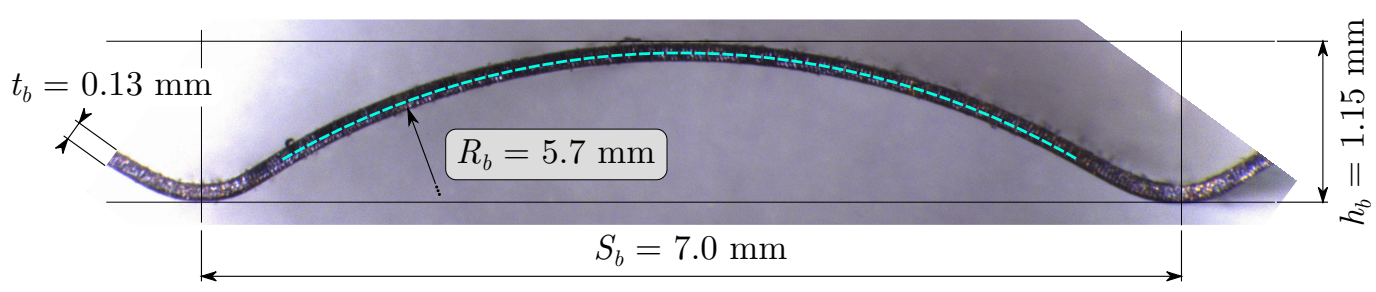

(b)

Figure 3: The applied bump foil schematics compared with a LOM photo of the actually used bump foil: (a) Schematics of the foil structure; and (b) light optical microscopy (LOM) photo of one bump using 20 times magnification superimposed with measurements.

$N_{b}+3$ are used for reaction force calculations only. The model uses six stiffness coefficients $k_{1}, k_{2}, k_{3}, k_{4}, k_{1 b}, k_{3 b}$ and two force transmission angles $\theta_{d}, \theta_{d b}$, where the " $b$ " postfix coefficients are particular to the last bump, i.e. that at the trailing edge. These eight coefficients are calculated using 33 analytical expressions resulting from a tedious derivation based on Castigliano's second theorem as presented by Le Lez et al. [31].

The test rig bump foil strips are unchanged from the previous work by the authors, but the foil geometry has been further investigated to minimise uncertainties. The dimensions included in the commonly used schematics in Fig. 3a are updated using a series of light optical microscopy (LOM) photos of the actual bump foil as the one shown in Fig. 3b. Knowing the LOM photo resolution from calibrations, the bump foil height $h_{b}$, the bump foil pitch $S_{b}$ and the foil thickness $t_{b}$ are found to be $7.0 \mathrm{~mm}, 1.15 \mathrm{~mm}$ and $0.13 \mathrm{~mm}$, respectively. The superimposed dashed arc results from a circle fit and indicates a radius of curvature $R_{b}$ of $5.7 \mathrm{~mm}$. No well-defined flat sections are present meaning that the half bump length $l_{0}$ given in the schematics is not directly measurable. This ambiguity is interesting considering e.g. the analytical bump foil stiffness by Walowit and Anno [47]

$$
k_{b}=\frac{E_{b}}{2 S_{b}}\left(\frac{t_{b}}{l_{0}}\right)^{3}\left(1-v_{b}^{2}\right)^{-1},
$$

which indicates an inverse proportionality to $l_{0}$ cubed. Furthermore, the lack of flat intermediate sections reduces the foil-housing contact regions to lines, contrary to areas or line-pairs often assumed in foil friction analyses [45, 48]. 
For consistency, $l_{0}$ is therefore calculated as the half length of a chord with sagitta $h_{b}$ in a circle with radius $R_{b}$ resulting in $3.43 \mathrm{~mm}$ and implying a bump half angle $\theta_{0}$ of $37^{\circ}$. Using these updated dimensions, the stiffness coefficients and transmission angles for representing the present bump foil geometry are given in Table 1.

Table 1: Stiffness coefficients and transmission angles of the truss structure obtained from the analytical expressions in [31] and foil geometry in Table 3.

\begin{tabular}{cccccccc}
\hline \multicolumn{4}{c}{ Stiffness coefficients $\left[\mathrm{MN} \mathrm{m}^{-1}\right]$} & \multicolumn{3}{c}{ Angles [ $\left.{ }^{\circ}\right]$} \\
$k_{1}$ & $k_{2}$ & $k_{3}$ & $k_{4}$ & $k_{1 b}$ & $k_{3 b}$ & $\theta_{d}$ & $\theta_{d b}$ \\
\hline 31.55 & 0.4285 & 2.289 & 4.992 & 12.53 & 1.755 & 19.97 & 23.77 \\
\hline
\end{tabular}

A thorough validation of the truss model was presented in [31], but to substantiate its applicability to the present bump foil geometry and to validate its current implementation, a comparison is made to results from a plane FE model (see Appendix C). The FE model geometry is extracted directly from Fig. $3 \mathrm{~b}$ and two load cases are included in which the bump foil strip is uniformly loaded in its initial straight and fitted curved state, respectively. This results in the normal, i.e. radial, bump stiffness listed in Table 2. The effect of fitting the foil strip into the bearing housing is found negligible (less than $2.5 \%$ ), and the agreement to the truss model is generally good. The observed discrepancy (42\%) for the first bump is ascribed to a $4 \mathrm{~mm}$ flat section of the foil strip at the leading edge, which is not taken into account by the truss coefficients. To capture this, a set of alternative coefficients similar to those for the last bump could be developed for the first one, but this has not been attempted. For comparison, the widely used analytical expression Eq. (18) predicts a uniform stiffness of $0.88 \mathrm{GN} \mathrm{m}^{-3}$.

Table 2: Comparison of effective stiffness resulting from the truss model and from the plane FE model presented Appendix C.

\begin{tabular}{lccccccccc}
\hline & \multicolumn{8}{c}{ Effective normal stiffness $k_{b}$ for each bump $\left[\mathrm{GN} \mathrm{m}^{-3}\right]$} \\
Model & 1 & 2 & 3 & 4 & 5 & 6 & 7 & 8 & 9 \\
\hline Truss, coefficients from Table 1 & 3.4 & 3.2 & 3.3 & 3.2 & 3.2 & 3.3 & 3.1 & 3.7 & 1.7 \\
Plane FE model, straight state & 2.4 & 3.6 & 3.2 & 3.3 & 3.3 & 3.3 & 3.1 & 4.5 & 1.6 \\
Plane FE model, fitted state & 2.4 & 3.7 & 3.2 & 3.3 & 3.3 & 3.4 & 3.1 & 4.4 & 1.6 \\
\hline
\end{tabular}

\subsubsection{Inclusion of Bump Foil Mass}

Inclusion of the foil mass is generally avoided for at least two good reasons: Firstly, the foil dynamics are insignificant to the desired rotordynamic response, and secondly, the low foil mass results in very high natural frequencies, posing a challenge to the numerical integration. Neglecting the foil mass, a set of purely algebraic equations is provided by the presented truss model, meaning that it has no inherent notion of time and hence that only (quasi-)static results can be obtained from its solution. If this foil model was coupled directly to the shaft and fluid film ODEs, the coupled equation system would obtain a singular Jacobian matrix, meaning that instead of being a system of ODEs, it would belong to the wider class of differential/algebraic equation (DAE) systems [49]. Even though the properties of DAEs are not as well understood as those of ODEs and no general guarantees regarding solution existence and uniqueness can be given [50], numerical solvers do exist for initial value problems for DAE systems [51-54].

For the present purpose, however, such a DAE formulation would lack the sliding velocities necessary for the coupling to a friction model. Theses could be reconstructed from the displacements through a number of previous time steps using FD, but this would break the simultaneity of the solution and reintroduce the need for temporal convergence studies. Instead, the foil mass is included to transform the foil structure algebraic equations into ODEs providing the velocities directly. Considering the schematics in Fig. 3a, this is achieved by estimating the foil mass per bump as the arc and flat section lengths multiplied by the foil's axial extension, thickness and density as

$$
m_{b}=\left(2 \theta_{0} R_{b}+S_{b}-2 l_{0}\right) L t_{b} \rho_{b}
$$

and lumping $\frac{1}{2} m_{b}$ to each DOF of the truss. This is a rough approximation compared with the distribution of mass in the physical bump foil, but since an accurate prediction of the bump foil dynamics is not of primary interest, this is 
deemed adequate. For comparison, a nine-bump truss model with lumped masses and the present bump foil dimensions, as given in Table 3, has its first three natural frequencies at 2.12, 4.97 and $5.52 \mathrm{kHz}$, while the aforementioned plane FE model equipped with consistent mass matrices gives $2.09,5.62$ and $6.16 \mathrm{kHz}$.

It should be noted that despite the present foil being relatively soft compared with other foil geometries usually found in the literature, its natural frequencies are still well separated from the frequency band of interest, in this case ranging up to approximately $500 \mathrm{~Hz}$. To alleviate the numerical burden of resolving the high-frequency modes of the bump foil, a stiffness proportional viscous damping is therefore added to the structure. As a main objective has been to discard viscous damping in favour of frictional dissipation, the added structural damping should be limited not to become significant within the frequency range of interest, but even a slight damping has proven very beneficial to the integration. At present, a stiffness proportional damping is added to provide a damping ratio of $\zeta=0.001$ at $500 \mathrm{~Hz}$, resulting in modal damping ratios for the first three natural frequencies of 0.004, 0.010 and 0.011 . Simulations have been performed using both $\zeta(500 \mathrm{~Hz})=0.0001$ and $\zeta(500 \mathrm{~Hz})=0.005$ without notable changes in the results.

\subsection{Top Foil Structural Model}

A top foil model is included to provide the distribution of fluid film pressure onto the underlying bump foil. The top foil is modelled using plane two-node Euler-Bernoulli beam elements without longitudinal stiffness, very similar to the one-dimensional model given in [32]. The stiffness matrix of such an element is given by Eq. (D.1).

As the radial top foil deflection corresponds to the compliant height $h_{c}$ in the fluid film equations, the top foil velocities are necessary for enforcing boundary conditions as discussed in Section 3.2. For this reason, the top foil mass is also included. This could be achieved using a consistent mass matrix, but since the number of elements in this matrix is decisive for the number of arithmetic operations required in each time step, it has proven advantageous to use a diagonal mass matrix instead. An approximate lumped matrix is given in Eq. (D.1). Furthermore, a stiffness proportional damping is added to the top foil as described for the bump foil structure in the previous section.

The beam representation of the top foil implies that curvature effects and membrane forces are neglected and that the bump foil-top foil contacts reduce to singular points. This implies an overestimation of the sagging effect and, according to San Andrés and Kim [32], the top foil Young's modulus should be multiplied by a factor of four to obtain a level of sagging comparable to the experimental results from [40]. Sagging has been shown to neither influence the linear stiffness coefficients [32] nor the obtained steady state equilibrium position [16] significantly, but it implies very large pressure gradients challenging the numerical integration. In the present work, artificial stiffening of the top foil, i.e. the mentioned multiplication by four, is avoided as far as possible, but for the cases to be presented with pinned bump foil, very high levels of sagging have prohibited numerical convergence without it.

\subsection{Assembled Foil Structural Model}

The bump and top foil elements are assembled into a single system representing the foil structure of an entire bearing as illustrated for a single pad with three bumps in Fig. 4. The bump and top foils are rigidly connected, meaning that foil separation is not permitted, and the top foil element length is chosen to match that of the fluid film. The upper leading edge node of the foil, which is pinned in the original model by Le Lez et al. [31], is flexibly supported by the linear and torsional springs of stiffness $k_{5}$ and $k_{6}$. Currently, the stiffness of these supports are chosen equivalent to those of a top foil beam element, i.e. $k_{5}=12 E_{t} I_{t} / l_{t}^{e 3}$ and $k_{6}=4 E_{t} I_{t} / l_{t}^{e}$.

A proper nondimensionalisation of the foil structure has proven critical to the time integration, especially with regard to the chosen length scale. It would have been convenient to use the same length scale as for the fluid film quantities, i.e. the clearance $C$, but this has proven unsuitable. Instead, the top foil element length $l_{t}^{e}$, which is in the order of $\frac{1}{8}$ to $\frac{1}{2}$ of the bump pitch, is used while the time and force scales are shared with the fluid film. Using these scales, the nondimensional foil structure displacements are collected in the vector $\tilde{\mathbf{x}}_{\alpha}$ for each bearing $\alpha=A, B$ and the foil structure is represented by the nondimensional mass, damping and stiffness matrices $\tilde{\mathbf{M}}_{f}$, $\tilde{\mathbf{D}}_{f}$ and $\tilde{\mathbf{K}}_{f}$. The vector of compliant heights $\tilde{\mathbf{h}}_{c}$ needed in the fluid model, and the main purpose of the foil model, is hence a subset of the foil structure displacement vector, $\tilde{\mathbf{h}}_{c} \subset \tilde{\mathbf{x}}$. The piecewise linear fluid film pressure is acting on the top foil beam elements through the vector of nondimensional work equivalent nodal loads $\tilde{\mathbf{f}}_{p}\left(\tilde{\mathbf{p}}_{\alpha}\right)$, calculated using Eq. (D.2).

To include the frictional forces, a vectorised version of the scalar friction force function Eq. (17) is obtained following four steps: (a) calculating the relevant normal forces from the bump foil's dynamic equilibrium, taking into account the reversed direction of the normal forces at the top foil interfaces; $(b)$ equating negative normal forces to 


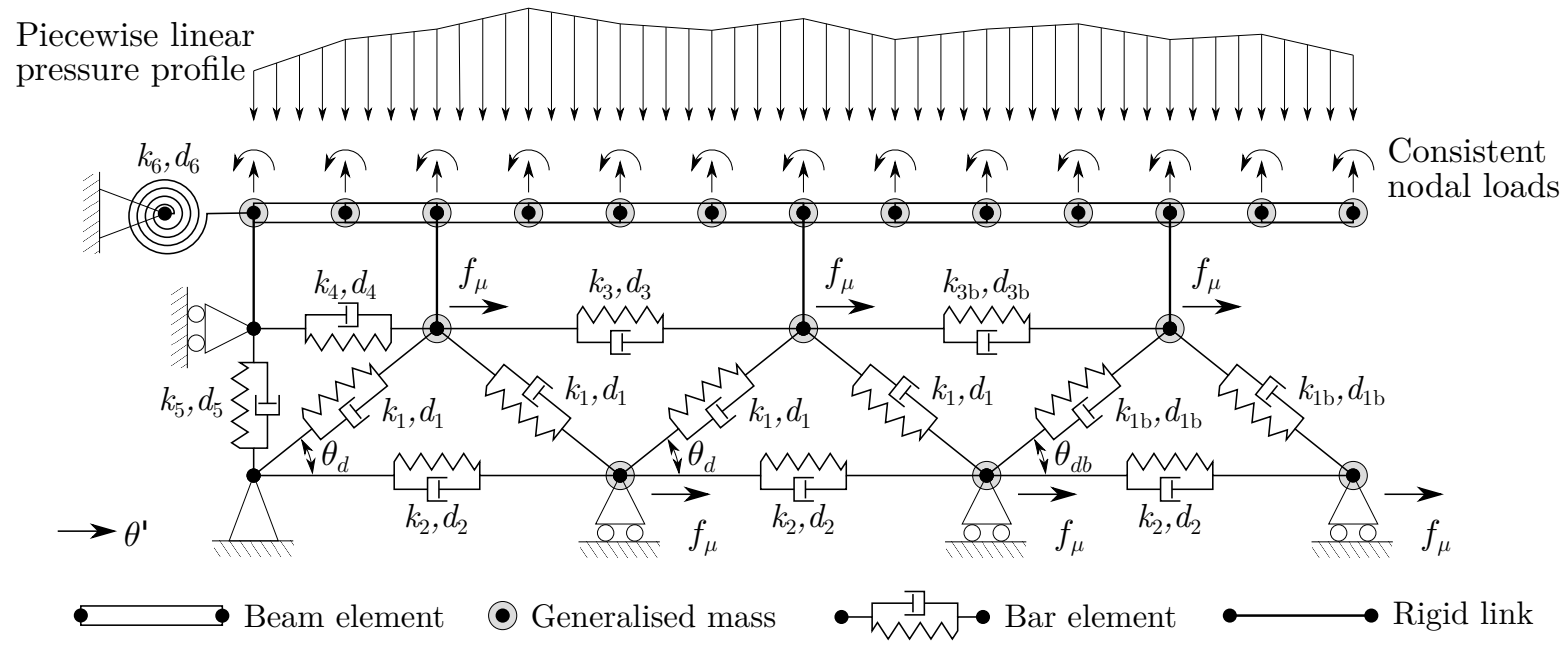

Figure 4: Illustration of foil structure model for three bumps

zero; $(c)$ associating the obtained normal forces to their relevant sliding DOFs; and $(d)$ calculating the friction force for each sliding DOF using Eq. (17). This procedure is represented by the friction force vector $\tilde{\mathbf{f}}_{\mu}\left(\tilde{\mathbf{x}}_{\alpha}, \dot{\mathbf{\mathbf { x }}}_{\alpha}, \ddot{\mathbf{x}}_{\alpha}, \tilde{\mathbf{p}}_{\alpha}\right)$.

With the external forces represented by $\tilde{\mathbf{f}}_{p}$ and $\tilde{\mathbf{f}}_{\mu}$, the foil structure's EOMs can be written as a system of nonlinear ODEs as

$$
\tilde{\mathbf{M}}_{f} \ddot{\tilde{\mathbf{x}}}_{\alpha}+\tilde{\mathbf{D}}_{f} \dot{\tilde{\mathbf{x}}}_{\alpha}+\tilde{\mathbf{K}}_{f} \tilde{\mathbf{x}}_{\alpha}=\tilde{\mathbf{f}}_{\mu}\left(\tilde{\mathbf{x}}_{\alpha}, \dot{\tilde{\mathbf{x}}}_{\alpha}, \ddot{\mathbf{x}}_{\alpha}, \tilde{\mathbf{p}}_{\alpha}\right)+\tilde{\mathbf{f}}_{p}\left(\tilde{\mathbf{p}}_{\alpha}\right) .
$$

By introducing the dimensionless foil state space vector

$$
\tilde{\mathbf{u}}_{\alpha}=\left\{\begin{array}{ll}
\tilde{\mathbf{x}}_{\alpha}^{T} & \dot{\mathbf{x}}_{\alpha}^{T}
\end{array}\right\}^{T},
$$

the EOM Eq. (20) can be reformulated into a system of first order ODEs as

$$
\dot{\tilde{\mathbf{u}}}_{\alpha}=\overbrace{\left[\begin{array}{cc}
\mathbf{0} & \mathbf{I} \\
-\tilde{\mathbf{M}}_{f}^{-1} \tilde{\mathbf{K}}_{f} & -\tilde{\mathbf{M}}_{f}^{-1} \tilde{\mathbf{D}}_{f}
\end{array}\right]}^{\tilde{\mathbf{u}}_{f}}+\left\{\tilde{\mathbf{M}}_{f}^{-1}\left(\mathbf{f}_{\mu}\left(\tilde{\mathbf{u}}_{\alpha}, \dot{\tilde{\mathbf{u}}}_{\alpha}, \tilde{\mathbf{p}}_{\alpha}\right)+\tilde{\mathbf{f}}_{p}\left(\tilde{\mathbf{p}}_{\alpha}\right)\right)\right\},
$$

which constitutes the governing equation of the foil structure including friction. The linear contribution is represented by the nondimensional and constant foil structure matrix $\tilde{\mathbf{A}}_{f}$ while the nonlinear contribution is given by the vector functions $\tilde{\mathbf{f}}_{p}$ and $\mathbf{f}_{\mu}$.

\section{Coupled System of ODEs}

Three sets of first order ODEs representing the rotor, fluid and foil structure domains have been established as given by Eqs. (4), (10) and (22). Introducing the global state vector

$$
\mathbf{y}=\left\{\begin{array}{llllll}
\boldsymbol{\psi}_{A}^{T} & \boldsymbol{\psi}_{B}^{T} & \tilde{\mathbf{u}}_{A}^{T} & \tilde{\mathbf{u}}_{B}^{T} & \mathbf{z}_{1}^{T} & \mathbf{z}_{2}^{T}
\end{array}\right\}^{T},
$$


these domains can be coupled to obtain a single system of nonlinear first order ODEs as

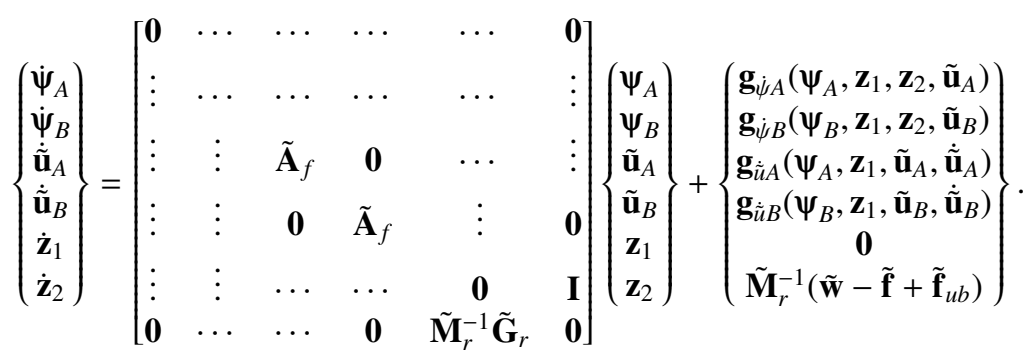

The nonlinear functions on the right hand side are defined from Eq. (10) as

$$
\mathbf{g}_{\dot{\psi} \alpha}\left(\psi_{\alpha}, \mathbf{z}_{1}, \mathbf{z}_{2}, \tilde{\mathbf{u}}_{\alpha}\right)=\boldsymbol{\Gamma}_{\alpha}^{-1} \mathbf{r}_{\alpha}
$$

and from Eq. (22) as

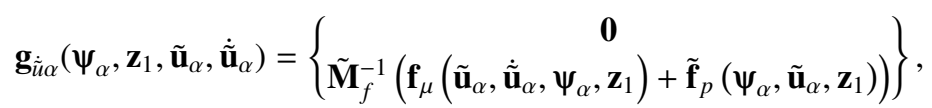

respectively.

\subsection{Numerical Implementation - An Overview}

The numerical integration of Eq. (24) is more time-consuming than for its SEFM based counterpart previously presented by the authors in [23, 29, 30], and an efficient implementation is necessary to obtain reasonable solution times. The implementation used for the present work is written mainly in $\mathrm{C}$ and the system of ODEs are solved using the "CVODE" linear multistep solver from the Sundials package [53]. A substantial reduction of integration time has been obtained by applying an iterative solution scheme to solve the linear system of equations required for each Newton-Raphson iteration within each time step. The Jacobian matrix is approximated numerically, but it is expected that an analytical expression for this, as used by Bonello and Pham [27], would provide a further significant speed-up.

Each evaluation of Eq. (25) requires the solution of a linear system of equations. This is achieved using LAPACK's band form routines to initially factorise the fluidity matrix $\boldsymbol{\Gamma}_{\alpha}$ and subsequently to obtain the solution from backsubstitution. For the assembly of $\mathbf{r}_{\alpha}$, it has proven beneficial to use a regular mesh as this allows the constant parts of the matrix-vector products from Eq. (11) to be shared between elements.

For evaluating Eq. (26), the reaction forces need to be obtained from the bump foil structure's dynamic equilibrium, requiring three matrix-vector products, and the inverse mass matrix should furthermore be multiplied by the sum of friction and pressure forces. To efficiently obtain these products, a compressed-sparse-row matrix format is used.

A limitation in the current implementation is the transfer of forces between the fluid film and top foil elements, as this requires the nodes of the two models to line up circumferentially. This means that separate convergence studies cannot be performed and hence that one of the domains must be meshed denser than necessary.

The numerical results presented in the following are calculated on a workstation equipped with a $3.5 \mathrm{GHz}$ Intel ${ }^{\circledR}$ Xeon $^{\mathrm{TM}}$ processor. For each bearing, the fluid film has been discretised using 819 nodes, while 576 degrees of freedom have been used for the foil structure. Including the rigid shaft, this gives 2798 equations. The time required to solve this system is strongly dependent on the model parameters, especially those related to damping and friction, but one second of simulation starting from a rotor-drop currently requires a few hours of computation.

\section{Results \& Discussion}

The following three sections present a number of results regarding the friction model, the frequency response of the rotor-bearing system and the unbalance response. All of these are based on the test rig data as given in Table 3 . 
Table 3: Geometry, material properties and operating conditions of the Siemens foil bearing test rig.

\begin{tabular}{lrlr}
\hline Shaft assembly & & & \\
Bearing $A$ to CG, $l_{1}$ & $201.1 \mathrm{~mm}$ & Mass, $m=m_{x}=m_{y}$ & $21.1166 \mathrm{~kg}$ \\
Bearing $B$ to CG, $l_{2}$ & $197.9 \mathrm{~mm}$ & Polar moment of inertia, $I_{z z}$ & $30.079 \times 10^{-3} \mathrm{~kg} \mathrm{~m}^{2}$ \\
Unbalance $A$ to CG, $l_{3}$ & $287.2 \mathrm{~mm}$ & Transverse moment of inertia, $I_{x x}=I_{y y}$ & $525.166 \times 10^{-3} \mathrm{~kg} \mathrm{~m}^{2}$ \\
Unbalance $B$ to CG, $l_{4}$ & $304.0 \mathrm{~mm}$ & & \\
\hline Bearing configuration & & & $30^{\circ}$ \\
Bearing radius, $R$ & $33.50 \mathrm{~mm}$ & First pad leading edge, $\theta_{l}$ & $145^{\circ}$ \\
Bearing length, $L$ & $53.00 \mathrm{~mm}$ & First pad trailing edge, $\theta_{t}$ & $30^{\circ}$ \\
Radial clearance, $C$ & $40 \mu \mathrm{m}$ & Slope extend, $\theta_{s}$ & $50 \mu \mathrm{m}$ \\
Number of pads, $N_{p}$ & 3 & Slope height, $h_{s}$ & \\
\hline Fluid properties & & & $1 \times 10^{5} \mathrm{~Pa}$ \\
Viscosity, $\mu$ & $1.95 \times 10^{-5} \mathrm{~Pa} \mathrm{~s}$ & Ambient pressure, $p_{a}$ & $7.00 \mathrm{~mm}$ \\
\hline Bump foil properties & & & $1.15 \mathrm{~mm}$ \\
Bump foil thickness, $t_{b}$ & $0.13 \mathrm{~mm}$ & Bump foil pitch, $S_{b}$ & 0.3 \\
Bump foil half length, $l_{0}$ & $3.43 \mathrm{~mm}$ & Bump foil height, $h_{b}$ & 0.05 \\
Young's modulus $E_{b}$ & $207 \mathrm{GPa}$ & Poisson's ratio, $v_{b}$ & $37^{\circ}$ \\
Radius of curvature, $R_{b}$ & $5.7 \mathrm{~mm}$ & Coefficient of friction, $\mu_{f}$ & \\
Density, $\rho_{b}$ & $8280 \mathrm{~kg} \mathrm{~m}{ }^{-3}$ & Bump half angle, $\theta_{0}$ & 0.3 \\
\hline Top foil properties & & & \\
Top foil thickness, $t_{t}$ & $0.254 \mathrm{~mm}$ & Poisson's ratio, $v_{t}$ & $8280 \mathrm{~kg} \mathrm{~m}^{-3}$ \\
Young's modulus $E_{t}$ & $2.07 \times 10^{11}$ Pa & Density, $\rho_{t}$ & \\
\hline
\end{tabular}

\subsection{The Foil Model}

The first results treat the friction function smoothing parameter $\gamma$. Too low a value effectively renders the function linear and provides viscous dissipation, while too high a value results in a very stiff problem difficult to solve. A series of rotor drops from the bearing centres is performed for varying values of $\gamma$ at $20 \mathrm{kRPM}$, resulting in a maximum foil deformation at the first drop as depicted in Fig. 5. The simulations are continued for $0.5 \mathrm{~s}$ while the transient part of the rotor trajectory decays and a steady state orbit forced by the unbalance is formed. In Fig. 6, the mean axial pressure $\tilde{p}_{m}$ is plotted as a function of the foil deformation $h_{c}$ at $\theta=180^{\circ}$ for three different values of $\gamma$. This point corresponds to the summit of bump three in the second pad, which is in the heaviest loaded region as seen in Fig. 5. Setting $\gamma$ to zero, effectively deactivating the friction model, the foil behaves linearly and no friction-induced hysteresis is present as shown in Fig. 6a. Fitting a line to the last $0.125 \mathrm{~s}$ reveals a local stiffness of $3.2 \mathrm{GN} \mathrm{m}^{-3}$, which is very close to the statically obtained values from Table 2 . Setting $\gamma=10^{2}$, the friction model is activated and a hysteresis loop opens up, although with rather smooth corners. A fit to the last $0.125 \mathrm{~s}$ gives a line that passes diagonally through the hysteresis loop indicating an increase in effective stiffness to $4.9 \mathrm{GN} \mathrm{m}^{-3}$ as illustrated in Fig. 6b. Further increasing $\gamma$, the corners of the hysteresis loop sharpen and the effective diagonal stiffness increases to $6.8 \mathrm{GN} \mathrm{m}^{-3}$, as shown for $\gamma=10^{5}$ in Fig. 6c. The same stiffness value and loop shape is obtained using $\gamma=10^{4}$ and $\gamma=10^{6}$, hence $\gamma=10^{4}$ is deemed adequate. Notice, however, that this value should be scaled consistently to the nondimensionalisation.

The right and left edges of the hysteresis loop are often associated to sticking, but it should be emphasised that the current model is not capable of producing a true stick-phase as a friction force is only present for non-zero sliding velocities. The stiffness experienced on the right edge of the shown hysteresis loops is around $10 \mathrm{GN} \mathrm{m}^{-3}$, which is dependent on the coefficient of friction $\mu_{f}$, but true sticking would provide an even higher stiffness. If the foil-housing contact nodes are pinned, a situation corresponding to permanent sticking is created providing no frictional dissipation at these nodes. Repeating the same rotor drop simulation with this configuration, the deformation-pressure plot shown in Fig. 6d is obtained. As the bump foil structure is stiffened significantly, the tendency towards sagging is increased. The very high pressures reported in Fig. $6 \mathrm{~d}$ are hence caused by a local pressure peak near the bump summit following a sagging-induced converging zone. The fitted line indicates an effective stiffness in the order of $26 \mathrm{GN} \mathrm{m}^{-3}$. 


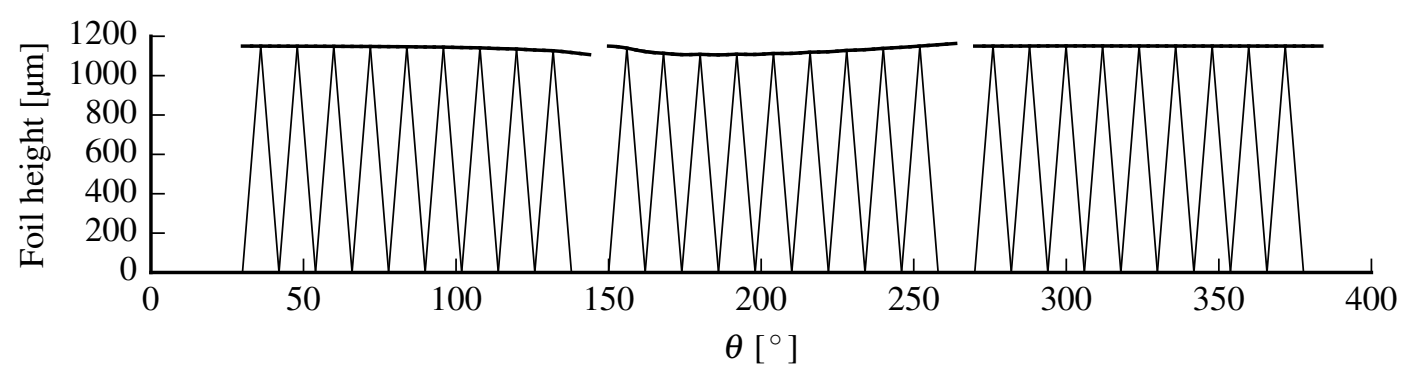

(a)

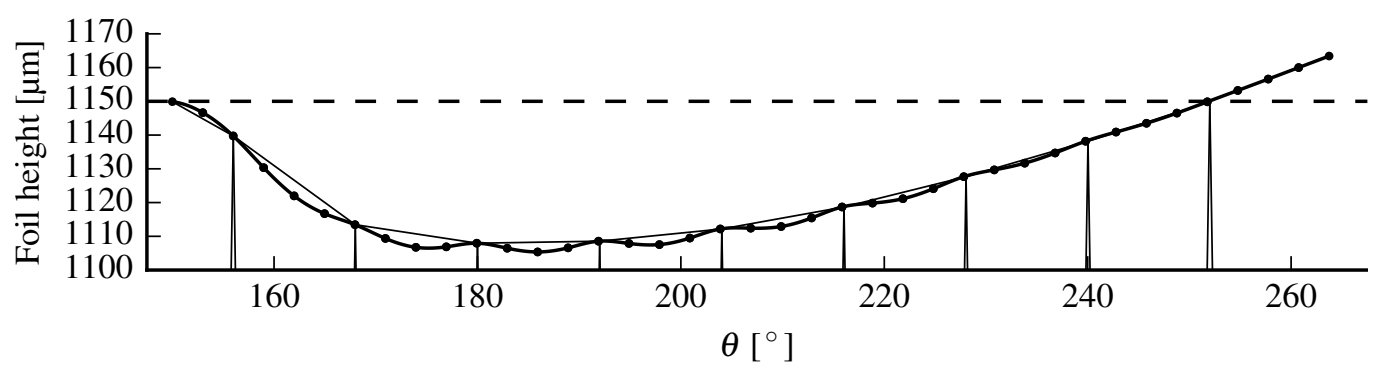

(b)

Figure 5: Excessive foil structure deformation at $\varepsilon_{x}, \varepsilon_{y}=1.98,0.121$ occurring $5.6 \mathrm{~ms}$ after the rotor is dropped from the centre: (a) The full foil structure; and (b) zoom to the midmost pad.

\subsection{Natural Frequencies}

The frequency response of the physical test rig has been thoroughly investigated. This provides a reference for validation of the numerical model. The experimental frequency response functions (FRFs) have been obtained using shaker excitation at the shaft extremities while maintaining a constant angular velocity. The excitation force amplitude was chosen to give a maximum displacement amplitude of $8 \mu \mathrm{m}$ in both the vertical and horizontal directions, as this provided an operable signal-to-noise ratio, while the behaviour remained reasonably linear. The experimental procedure is further described in [37], while the current results are given from [55].

The numerical receptance FRF matrix is obtained by applying $0-300 \mathrm{~Hz}$ linear chirps at the extremities with force amplitudes chosen to provide maximum displacement amplitudes of $8 \mu \mathrm{m}$. The magnitude and phase of the diagonal elements of this FRF matrix are shown in Fig. 7. The first two identifiable modes are located at $\approx 79 \mathrm{~Hz}$ and $\approx 105 \mathrm{~Hz}$, respectively, with the first being a cylindrical and the second a conical mode. The third mode at $\approx 146 \mathrm{~Hz}$ is much more heavily damped and completely absent when exciting in the horizontal $y$-direction. It has not been possible to identify the expected fourth mode theoretically, but this has not been observed experimentally either. A comparison to the experimentally observed natural frequencies for the three identifiable modes is given in Table 5.

Table 4: Comparison of experimentally observed and numerically predicted natural frequencies at $20 \mathrm{kRPM}$

\begin{tabular}{lccc}
\hline Mode & 1 & 2 & 3 \\
\hline Shape & Cylindrical & Conical & Cylindrical \\
Experimental observations [Hz] & $64-77$ & $104-119$ & $153-158$ \\
Numerical [Hz] & $78-80$ & $103-108$ & $146-147$ \\
Mid-interval deviation [\%] & +12 & -5 & -6 \\
\hline
\end{tabular}

\subsection{Unbalance Response}

The unbalance response has been obtained experimentally by attaching various unbalances to the $A$-disc, accelerating the rotor to $27 \mathrm{kRPM}$, disabling the electrical motor and measuring the response during the following coast 


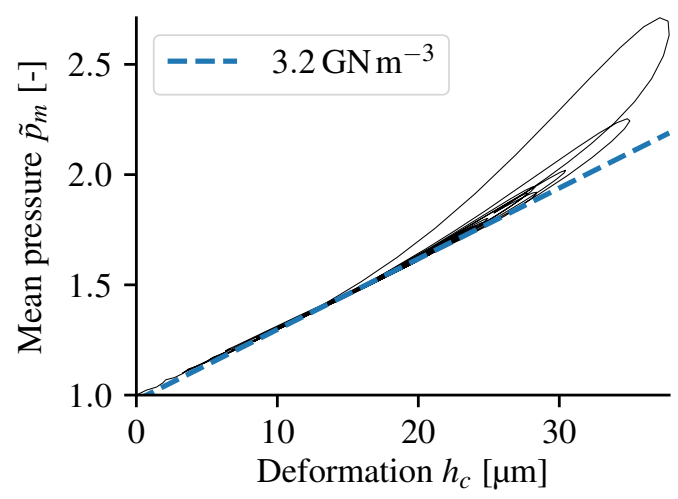

(a)

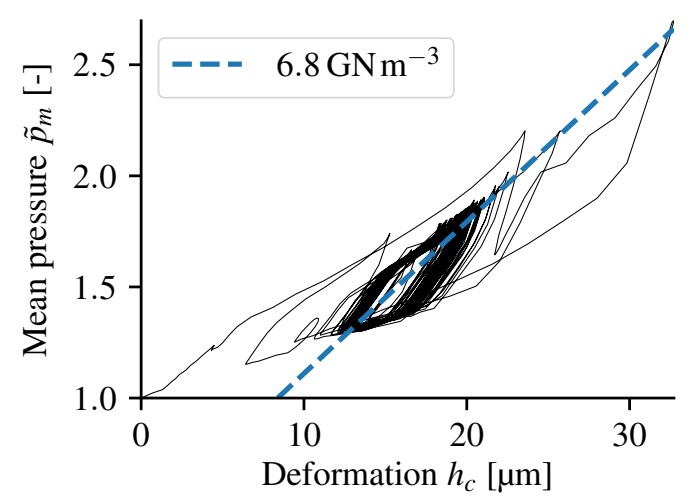

(c)

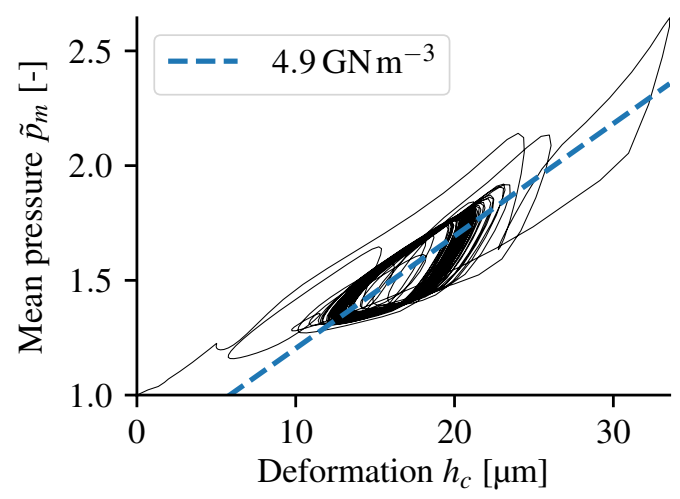

(b)

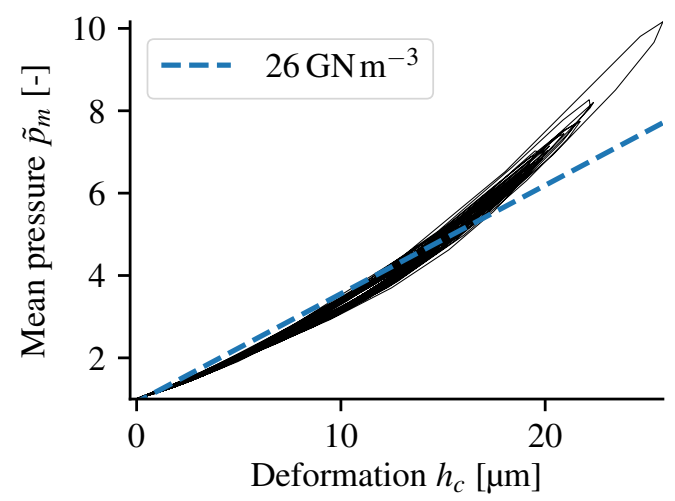

(d)

Figure 6: Hysteresis curves at the summit of bump three in the second pad segment $\left(\theta=180^{\circ}\right)$ for $0.5 \mathrm{~s}$ of simulation from a rotor drop from the centre using different smoothing parameter values: (a) $\gamma=0$; (b) $\gamma=10^{2}$; (c) $\gamma=10^{5}$; and (d) pinned foil-housing contact nodes. The dashed lines are fits to the last $0.125 \mathrm{~s}$ and indicate the local effective foil stiffness. Notice the different vertical scale in (d). This is made with pinned foil-housing contact nodes to simulate sticking which implies high sagging-induced pressure peaks.

down. The coast down approach is chosen to eliminate any contribution from the motor. The waterfall diagram obtained using the maximum applied unbalance of $45.5 \mathrm{~g} \mathrm{~mm}$ is shown in Fig. 8 for the vertical vibration in bearing $A$. The synchronous and a number of super-synchronous components are present at all velocities, while various sub-synchronous components, mostly arranged symmetrically about one half the synchronous speed $(0.5 \mathrm{X})$, appears and disappears sporadically. A single $0.5 \mathrm{X}$ vibration emerges at $9.5 \mathrm{kRPM}$ before it briefly disappears and bifurcates into two branches around 11.5 kRPM. At $14.6 \mathrm{kRPM}$, the two branches reunite only to bifurcate yet again around $16.2 \mathrm{kRPM}$ and eventually reunite at $22.5 \mathrm{kRPM}$. These rotational speeds are marked with thick black lines.

The waterfall diagram is obtained numerically by simulation of $1.3 \mathrm{~s}$ from a rotor drop from the centre for every 250 RPM. Discarding the first $0.3 \mathrm{~s}$ of each simulation, steady state is assumed to have been reached and FFTs are calculated for the remaining $1 \mathrm{~s}$. The residual unbalance is estimated to be less than $\pm 2.5 \mathrm{~g} \mathrm{~mm}$ at each end, and even if the unbalance mass is assumed to be added in the angle giving the highest possible effective unbalance of $U_{A}=48 \mathrm{~g} \mathrm{~mm}$ and $U_{B}=-2.5 \mathrm{~g} \mathrm{~mm}$, the model is unable to predict the sub-synchronous unbalance response correctly. The predicted waterfall diagram is shown in Fig. 9, and even though some sub-synchronous vibration is present in the 7-10 kRPM range, this is dissimilar to the experimentally observed pattern of bifurcations and reunifications. Increasing the coefficient of friction $\mu_{f}$, it is possible to shift this RPM range with sub-synchronous vibrations slightly upwards, but no qualitative changes to the waterfall appearance are obtainable.

One possible explanation for the absence of sub-synchronous activity could be an overestimation of the frictional damping. To test this, the waterfall is reproduced with $\gamma=0$ resulting in the waterfall diagram shown in Fig. 10. The 


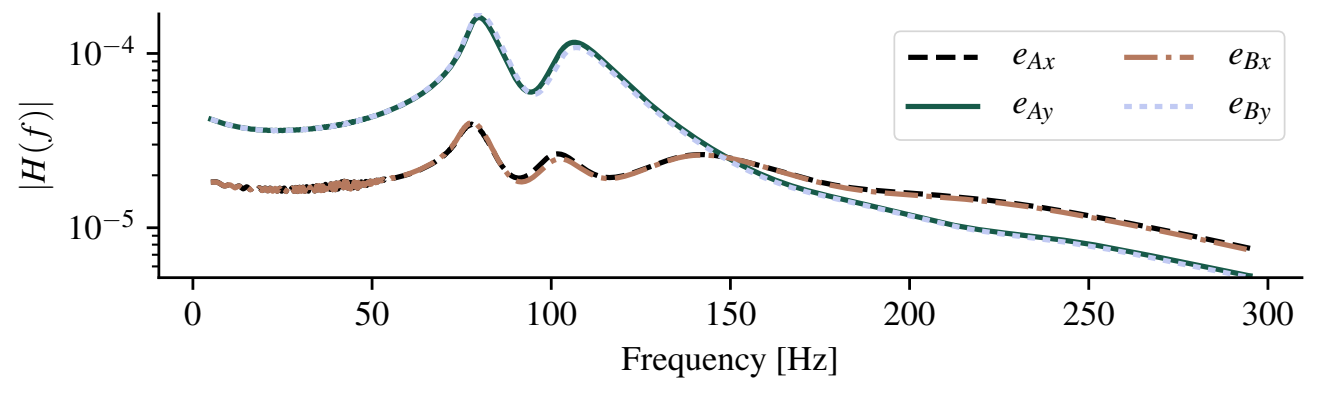

(a)

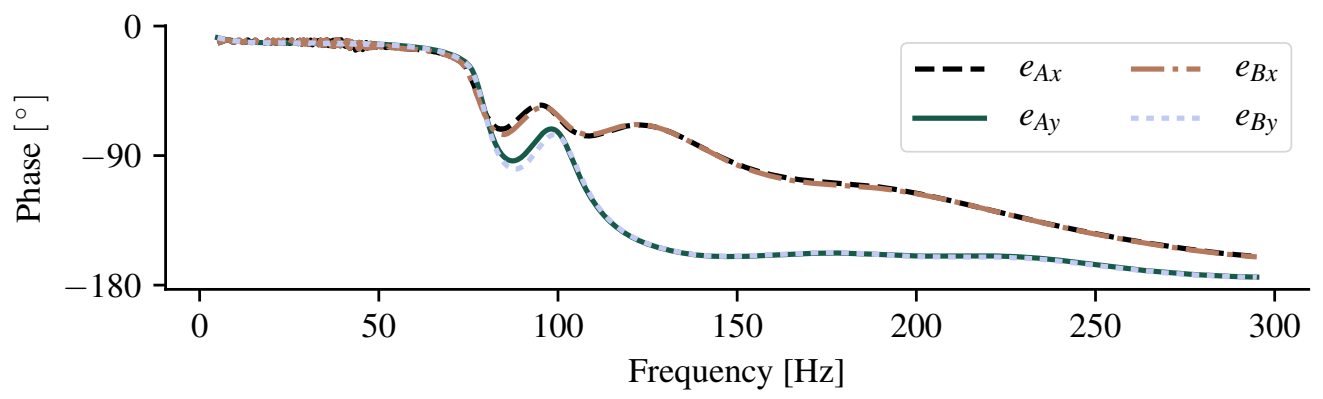

(b)

Figure 7: The diagonal elements of the numerically obtained receptance FRF matrix, i.e. the response of each DOF when it is excited directly.

damping is clearly lowered, as a $75 \mathrm{~Hz}$ natural frequency becomes visible and the solver has difficulties completing the integration for velocities less than 10 kRPM. The sub-synchronous vibrations visible from 13.5 to $14.8 \mathrm{kRPM}$ resemble the experimental results reasonably well, but much is still left to be desired.

A second possible explanation could be related to the aforementioned lack of true sticking. If sticking is in fact

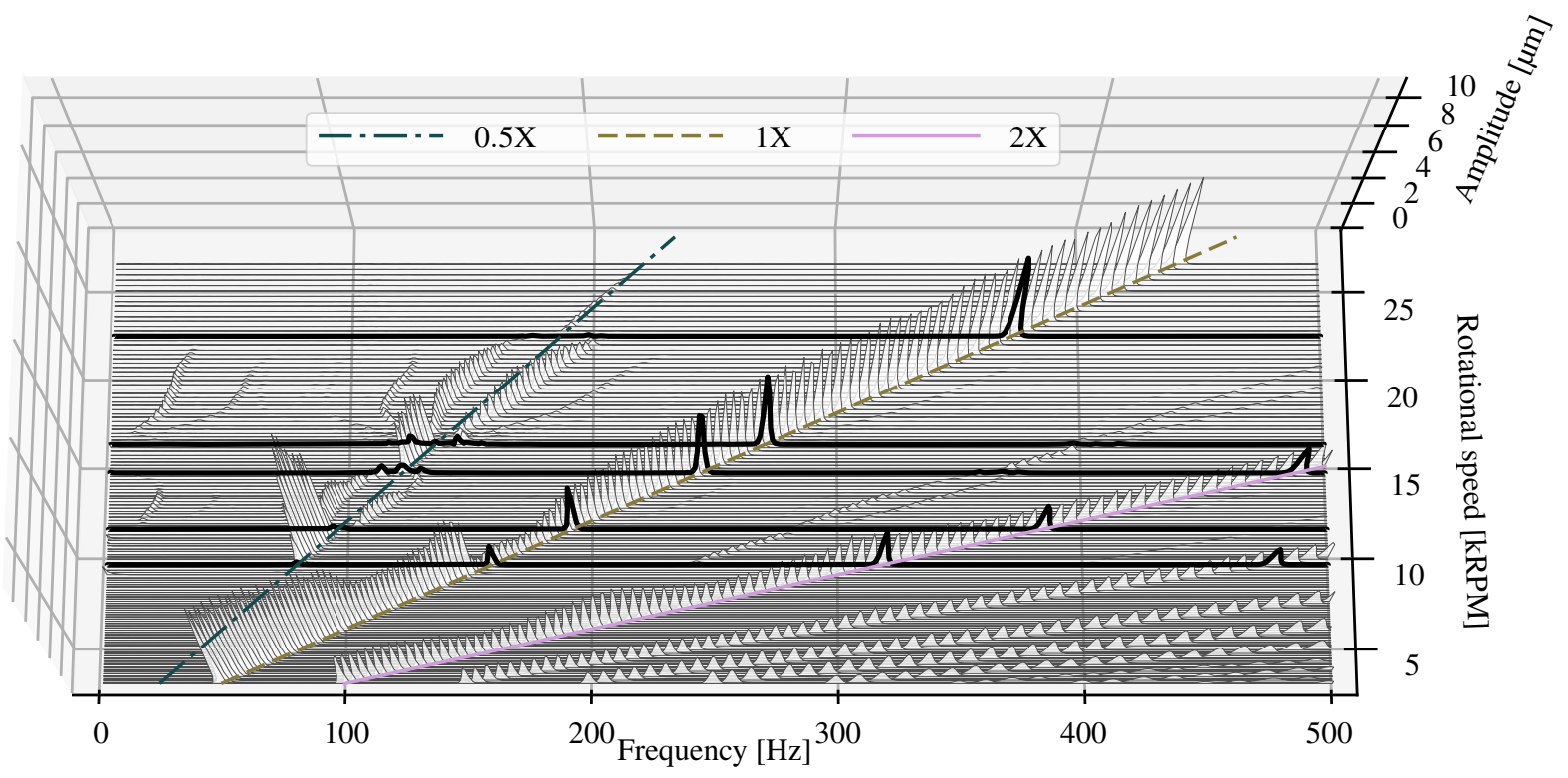

Figure 8: Experimentally obtained waterfall diagram for the vertical vibration in bearing $A$ showing the unbalance response during a coast down with $45.5 \mathrm{~g} \mathrm{~mm}$ added to the $A$ disc. The velocities marked with thick black lines are 9.5, 11.5, 14.6, 16.2 and $22.4 \mathrm{kRPM}$, respectively. 


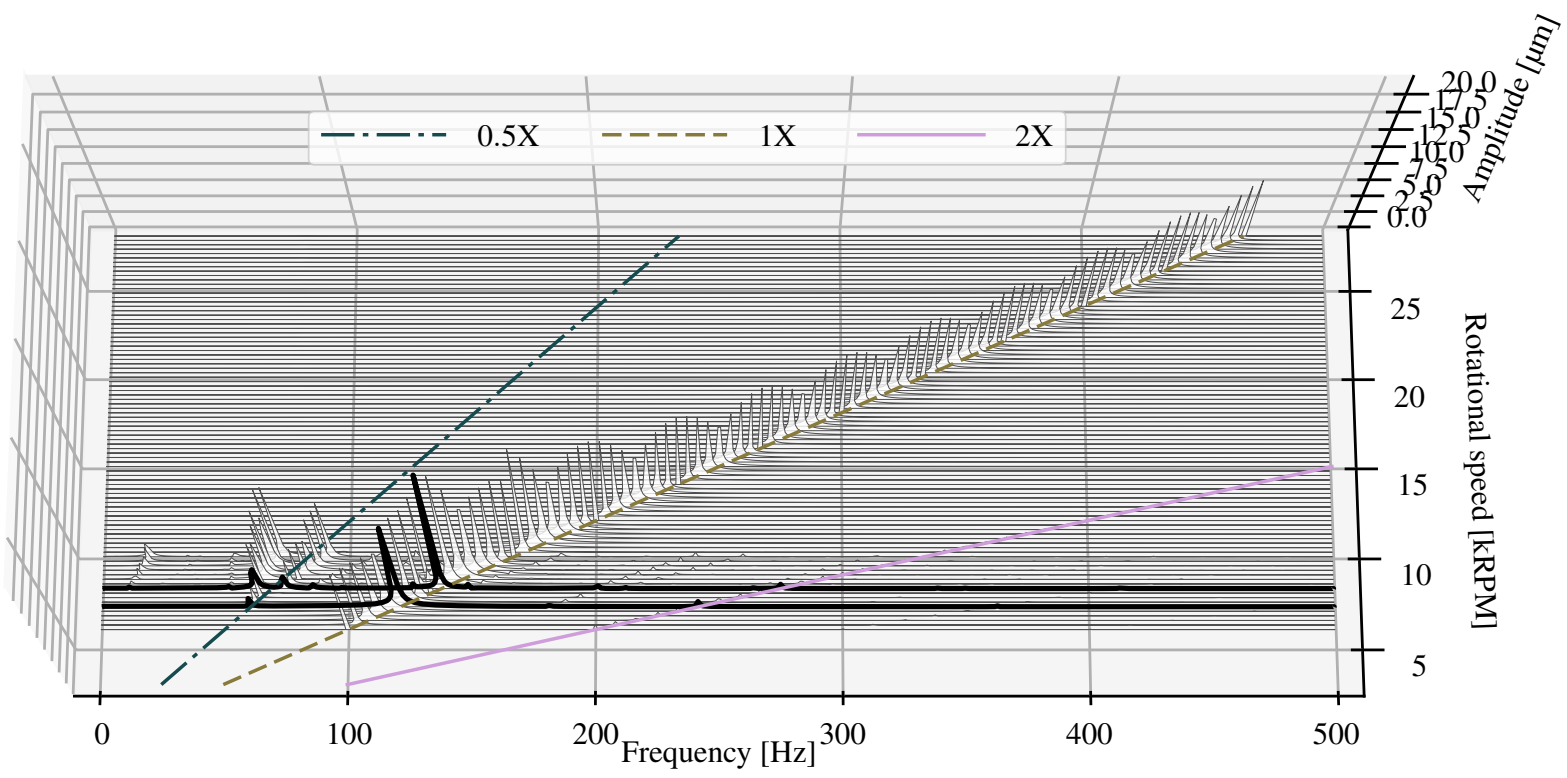

Figure 9: Waterfall diagram obtained numerically with properties as given in Table 3 and unbalance masses of $U_{A}=48 \mathrm{~g} \mathrm{~mm}$ and $U_{B}=-2.5 \mathrm{~g} \mathrm{~mm}$. The $0.5 \mathrm{X}$ vibration appears at $7.3 \mathrm{kRPM}$ and bifurcates at $8.3 \mathrm{kRPM}$, as marked with thick black lines. No sub-synchronous vibration is visible after $10 \mathrm{kRPM}$

a prevalent state, the current model will both underestimate the stiffness and overestimate the frictional dissipation. This is tested by performing the simulation yet again with the foil-housing contact nodes pinned, corresponding to permanent sticking. This is obviously unrealistic and it eliminates the frictional dissipation at the foil-housing interface entirely, but it serves to indicate what prevalent sticking would imply. The waterfall diagram from this simulation is shown in Fig. 11, and the similarity to the experimental results is notable even though the solver has difficulties integrating past $22 \mathrm{kRPM}$ due to the low damping. The $0.5 \mathrm{X}$ vibration emerges at $9 \mathrm{kRPM}$, bifurcates at $12 \mathrm{kRPM}$, reunites at $14.25 \mathrm{kRPM}$ and re-bifurcates at $15.5 \mathrm{kRPM}$. Zoomed views on the region with sub-synchronous

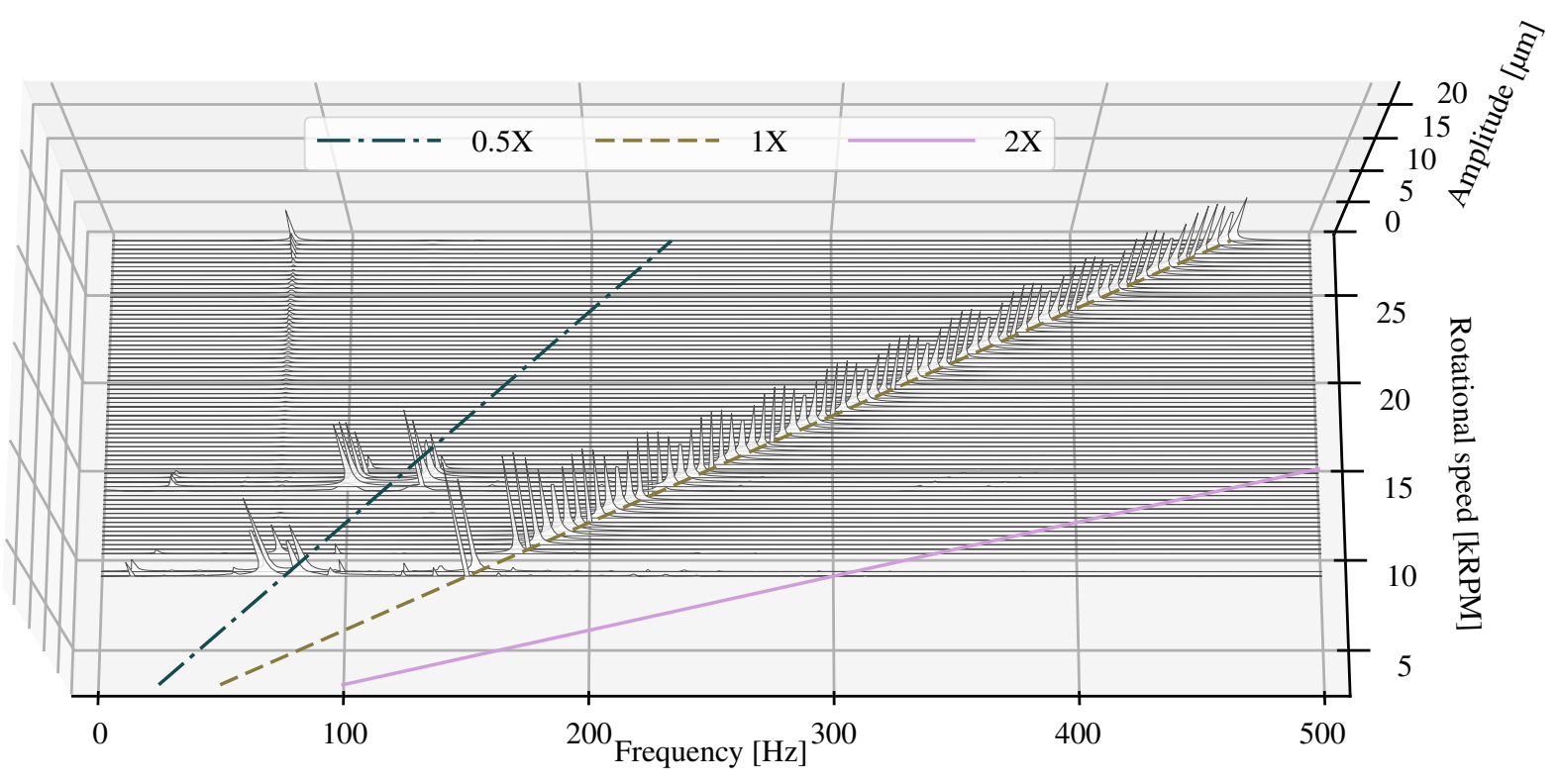

Figure 10: Waterfall diagram from the same configuration as in Fig. 9, but friction disabled, i.e. $\gamma=0$. 


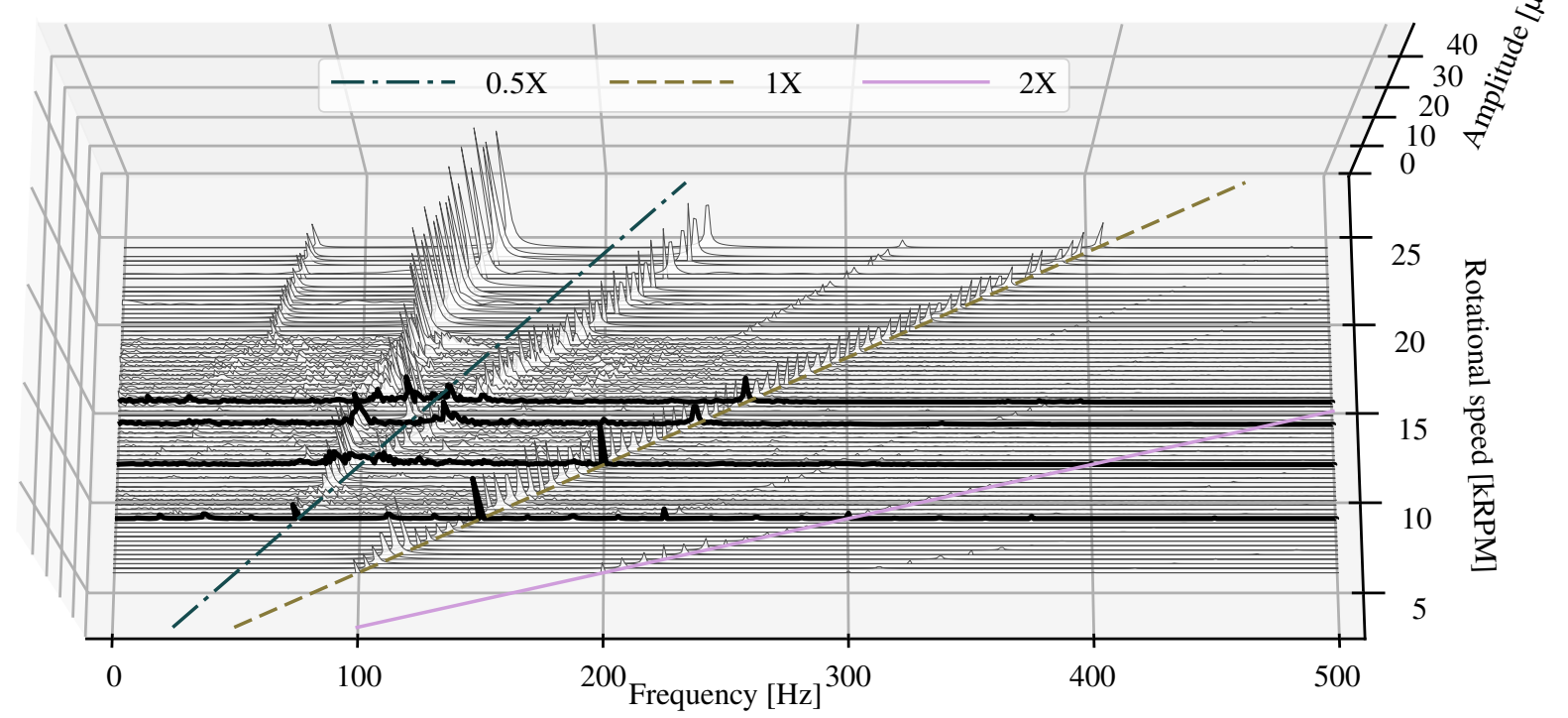

Figure 11: Waterfall diagram from the same configuration as in Fig. 9, but with pinned foil-housing contact nodes, as it is also the case in Fig. 6d. The velocities marked with thick black lines are 9, 12, 14.25 and $15.5 \mathrm{kRPM}$, respectively.

vibrations is also shown in Fig. 12. The qualitative behaviour of the simulated results are the same as observed experimentally, and a comparison of the angular velocities at the bifurcation events are given in Table 4 . These angular velocities are predicted within approximately $5 \%$, but the final reunion of the two branches around $22.5 \mathrm{kRPM}$ is not captured and the branches are too widely spaced. It should also be noted that the increased bump foil stiffness implied by the pinning causes excessive sacking which produces very large pressure peaks. Hence, the numerical solution has necessitated an artificial stiffening of the top foil to smooth the pressure profile, but this has been found not to influence the remaining results.

Table 5: Comparison of the angular velocities of four clearly defined events between the experimental data and the numerical simulation with pinned bump foil.

\begin{tabular}{lcc}
\hline Event & Experimental - Fig. 8 & Numerical (pinned) - Fig. 11 \\
\hline First appearance of 0.5X [kRPM] & 9.5 & 9 \\
First bifurcation [kRPM] & 11.5 & 12 \\
Reunification [kRPM] & 14.6 & 14.25 \\
Second bifurcation [kRPM] & 16.2 & 15.5 \\
\hline
\end{tabular}

Lastly, it is worth showing the difference in obtained steady state orbits between the three assessed cases, i.e friction, no friction and pinning. These are shown for 11 and $20 \mathrm{kRPM}$, respectively, in Fig. 13. The two non-pinned cases give almost identical one-periodic orbits with mean eccentricity ratios $\left(\varepsilon_{x}, \varepsilon_{y}\right)=(1.25,0.11)$ and $\left(\varepsilon_{x}, \varepsilon_{y}\right)=$ $(1.22,0.14)$ at $11 \mathrm{kRPM}$, and $\left(\varepsilon_{x}, \varepsilon_{y}\right)=(1.16,0.21)$ and $\left(\varepsilon_{x}, \varepsilon_{y}\right)=(1.13,0.22)$ at $20 \mathrm{kRPM}$. The pinned case gives much larger orbits with multiple clearly defined periods and with mean eccentricity ratios of $\left(\varepsilon_{x}, \varepsilon_{y}\right)=(0.60,0.15)$ at $11 \mathrm{kRPM}$, and $\left(\varepsilon_{x}, \varepsilon_{y}\right)=(0.29,0.12)$ at $20 \mathrm{kRPM}$.

Moreover, for $20 \mathrm{kRPM}$, the equilibrium points reached, if removing the unbalance, are furthermore indicated for each case. It is noticeable that the same static equilibrium $\left(\varepsilon_{x}, \varepsilon_{y}\right)=(1.17,0.22)$ is reached for both $\gamma=0$ and $\gamma=10^{4}$, even though a much higher effective stiffness is present in the latter, as previously shown in Fig. 6 . This is ascribed to the dynamic nature of the applied friction model, which cannot provide a friction force without a non-zero sliding velocity. 


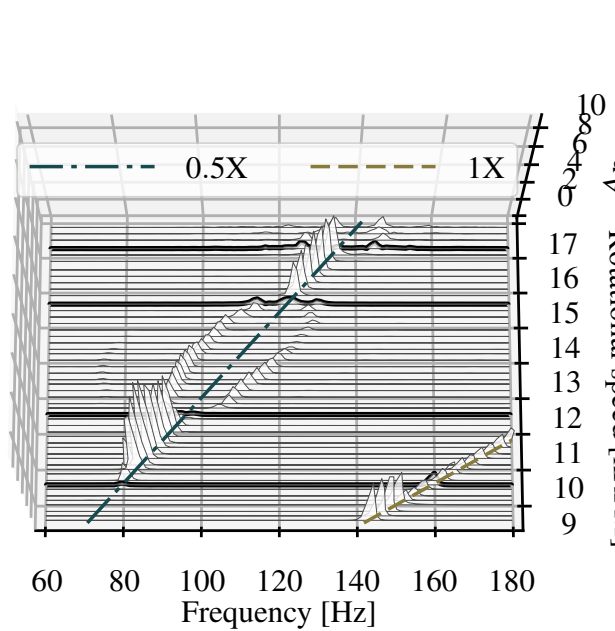

(a)

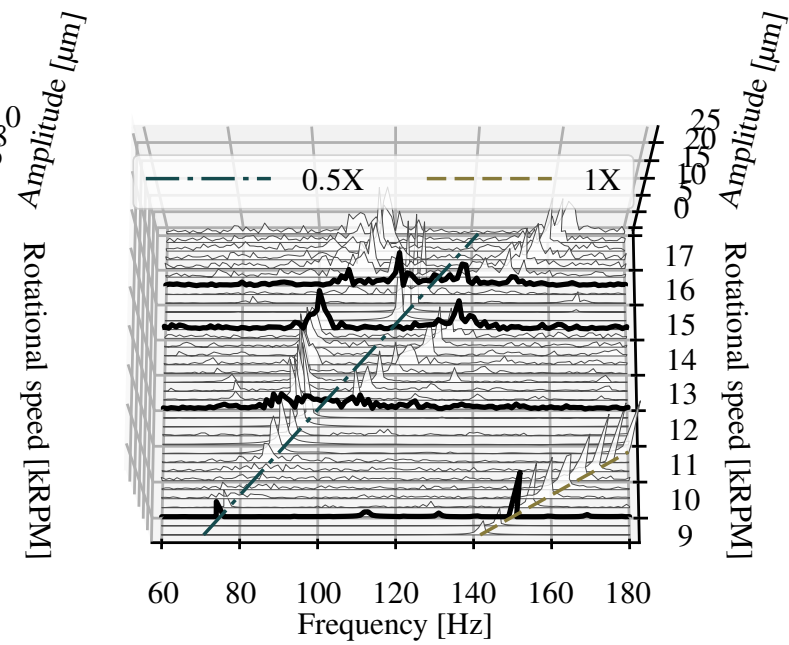

(b)

Figure 12: Zoomed views on the region with sub-synchronous activity from the experimental and the numerical (with pinned bump foil) waterfalls: (a) From Fig. 8, i.e. the experimental data; and (b) from Fig. 11, i.e. the pinned numerical case.

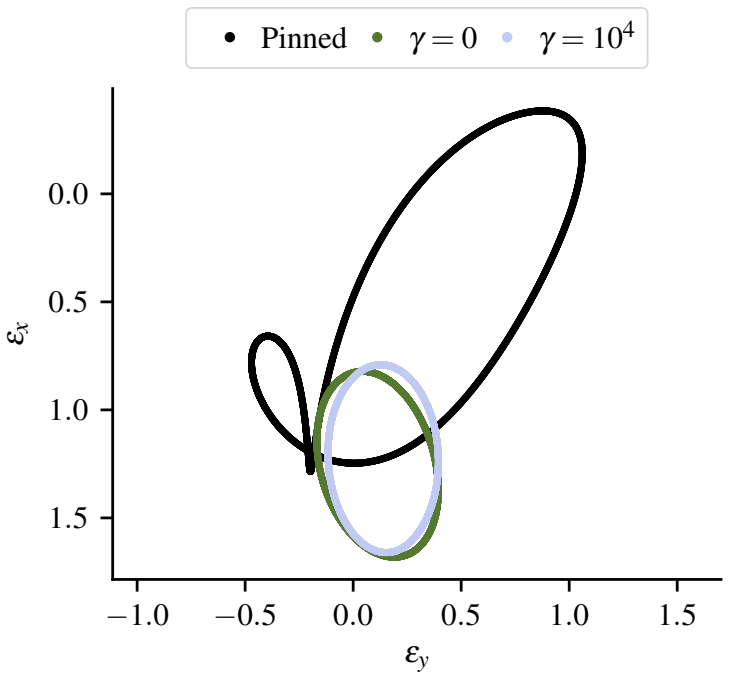

(a)

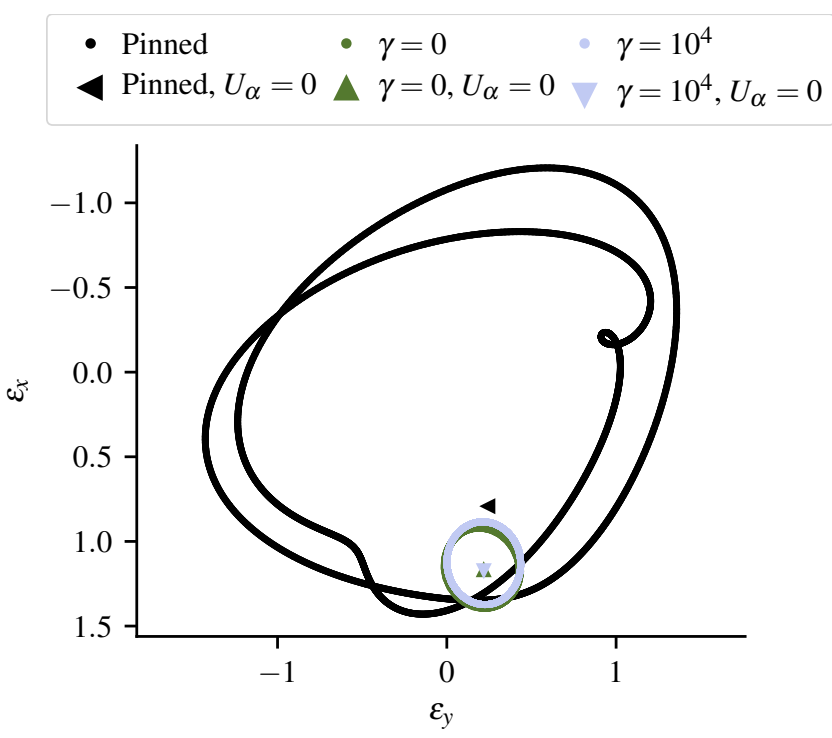

(b)

Figure 13: Comparison of steady state orbits with friction (Fig. 9), without friction (Fig. 10), and with pinned foil-housing contact nodes (Fig. 11): (a) $11 \mathrm{kRPM}$; and (b) $20 \mathrm{kRPM}$, where the equilibrium points reached if removing the unbalance are furthermore shown.

\section{Conclusions}

The paper has presented a nonlinear time domain model of a rigid shaft supported by AFBs. The compliant foil structure is included using an extended model based on the original idea of Le Lez et al. [31], coupled to a simple top foil beam model. The frictional energy dissipation at the top foil-bump foil and bump-foil-housing interfaces is included using a dynamic friction model and, in order to achieve a fully simultaneous solution of the state variables, the foil structure mass has also been included. The latter is argued to be a necessary addition since all friction models known to the authors encompass velocity dependencies, and hence a timescale is necessary. Separately, simultaneous models and models including friction already exist in the literature, but the presented model succeeds in reconciling these properties. The model has been demonstrated to be numerically realisable, though dependent on an efficient 


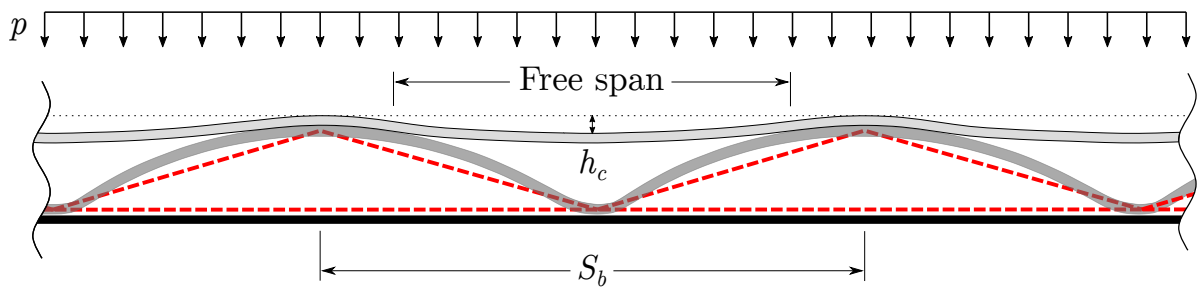

Figure 14: Illustration of top foil sagging. The top foil-bump foil contact zones have non-zero width, meaning that the effective free span between bump summits becomes smaller than the bump pitch $S_{b}$. The dashed (red) triangles illustrate the bump foil truss model which supports the top foil beam model only at singular points spaced $S_{b}$ apart.

implementation.

Based on directly measurable quantities and without the "engineering assumptions" related to the SEFM, the dynamics of the rotor-bearing system is captured well in terms of natural frequencies and mode shapes. The unbalance response, however, has not yet been captured satisfactorily using the current friction model. It is postulated that this is due to the characteristics of the applied dynamic friction model, as it tends to provide low-lying orbits corresponding to the frictionless situation. It is inconvenient that the absolute placement of the journal is hard to obtain experimentally within the required accuracy, and hence that it is difficult to assess whether the orbits obtained with friction are realistic. If the bump foil is pinned to the housing, effectively disabling friction at these contacts while providing a constant stiffness similar to that at sticking, promising results have been achieved. This is not a workable approach for general AFB simulation, but it suggests that sticking, which cannot be captured accurately using the dynamic friction model, is in fact a prevalent state. This is interesting as widespread sticking would be incompatible with the generally accepted perception of frictional dissipation as a main source of damping in AFBs.

Regarding friction, further work should be focused on incorporating a friction model similar to e.g. Eq. (16), in order to further assess the sticking behaviour. Also, experimental recordings of the bump foil sliding in operation would be of great value. Regarding the top foil, its stiffness has been found negligible in comparison to that of the bump foil, but numerical difficulties have been experienced due to excessive sagging causing high local pressure gradients. The overestimated sagging is partly caused by the omission of curvature effects and membrane forces, but comparing the model's pointwise top foil supports to the non-zero width contact zones of the actual foil as sketched in Fig. 14, it is possible that a contribution is also stemming from an overestimation of the free span. This would be important, as the deflection of a uniformly loaded clamped-clamped beam is proportional to its free span to the power of four. The excessive sagging has previously been investigated in [32], where a correction factor on the top foil's Young's modulus was introduced by fitting to experimental data, but a more generic approach is desirable. A point of attention for further work should hence be the implementation of an improved top foil formulation, possibly based on shell elements as presented in [56], if not only to provide numerical stability and speed up the simulation. 


\section{Appendix A. Rotor Model Matrices}

The mass and gyroscopic matrices for a rigid rotor can be written as

$$
\mathbf{M}_{r}=\frac{1}{l_{12}^{2}}\left[\begin{array}{cccc}
l_{2}^{2} m_{x}+I_{y y} & 0 & l_{1} l_{2} m_{x}-I_{y y} & 0 \\
0 & l_{2}^{2} m_{y}+I_{x x} & 0 & l_{1} l_{2} m_{y}-I_{x x} \\
l_{1} l_{2} m_{x}-I_{y y} & 0 & l_{1}^{2} m_{x}+I_{y y} & 0 \\
0 & l_{1} l_{2} m_{y}-I_{x x} & 0 & l_{1}^{2} m_{y}+I_{x x}
\end{array}\right], \quad \mathbf{G}_{r}=\frac{1}{l_{12}^{2}}\left[\begin{array}{cccc}
0 & -I_{z z} & 0 & I_{z z} \\
I_{z z} & 0 & -I_{z z} & 0 \\
0 & I_{z z} & 0 & -I_{z z} \\
-I_{z z} & 0 & I_{z z} & 0
\end{array}\right]
$$

where $l_{12}=l_{1}+l_{2}$. The nondimensional form of the mass and gyroscopic matrices and the mass unbalance vector are:

$$
\tilde{\mathbf{G}}_{r}=\frac{\omega^{2} C}{p_{a} R^{2}} \mathbf{G}_{r}, \quad \tilde{\mathbf{M}}_{r}=\frac{\omega^{2} C}{p_{a} R^{2}} \mathbf{M}_{r}, \quad \tilde{\mathbf{f}}_{u b}=\left\{\begin{array}{l}
\frac{U_{A} \omega^{2}}{p_{a} R^{2}}\left\{\begin{array}{c}
\cos \tau \\
\sin \tau
\end{array}\right\} \\
\frac{U_{B} \omega^{2}}{p_{a} R^{2}}\left\{\begin{array}{c}
\cos \tau \\
\sin \tau
\end{array}\right\}
\end{array}\right\}
$$

\section{Appendix B. Bump Foil Matrix}

The truss structure members are modelled as two-node bar elements with four DOFs. The stiffness matrix of a bar element with axial stiffness $k_{j}$ (representing $k_{1}, k_{2}, k_{3}, k_{4}, k_{1 b}$ or $k_{3 b}$ ) and angular orientation $\theta_{j}$ (representing $\theta_{d}$ or $\theta_{d b}$ ) is given from [39] as

$$
\mathbf{K}_{b}^{e}=k_{j}\left[\begin{array}{cccc}
\cos ^{2} \theta_{j} & \cos \theta_{j} \sin \theta_{j} & -\cos ^{2} \theta_{j} & -\cos \theta_{j} \sin \theta_{j} \\
& \sin ^{2} \theta_{j} & -\cos \theta_{j} \sin \theta_{j} & -\sin ^{2} \theta_{j} \\
& & \cos ^{2} \theta_{j} & \cos \theta_{j} \sin \theta_{j} \\
& & & \sin ^{2} \theta_{j}
\end{array}\right],
$$

where the elements below the diagonal are given from symmetry.

\section{Appendix C. Validation of Bump Model}

The FE model used for validation is created using a commercial software package and utilises plane quadratic quadrilateral elements, includes large displacement theory and assumes a state of plane strain. Its geometry is extracted directly from the LOM photo in Fig. 3b, but a $4 \mathrm{~mm}$ flat section is added to the leading end as present on the actual foil strips. Discarding friction, a nine-bump foil strip is clamped at its leading edge and subjected to uniform normal loads at the bump summits up to the equivalent of $200 \mathrm{kPa}$ in two different cases. In the first case, the undeformed and stress-free foil strip is supported by a straight rigid surface as shown in Fig. C.15a. In the second case, the foil strip is preloaded to fit a curved rigid surface, representing the bearing hosing as illustrated in Fig. C.15b. For both cases, a converged mesh is used.

In the applied load range, giving normal deformations up to $125 \mu \mathrm{m}$, no significant geometrical nonlinearity is observed and the stress level stays well below the yield strength. 


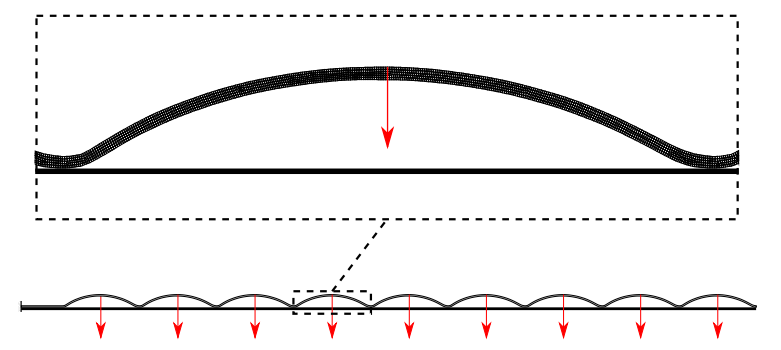

(a)

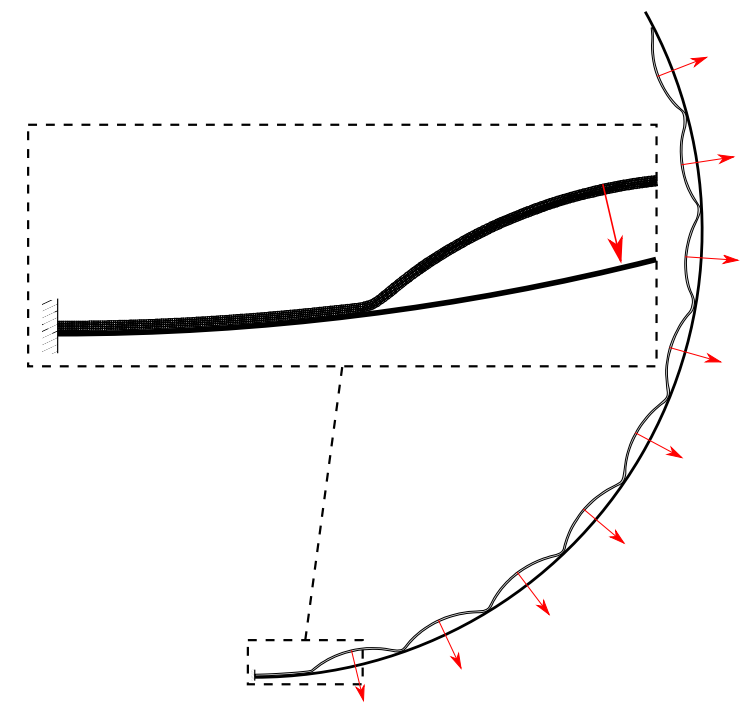

(b)

Figure C.15: The plane element FE model in its two load cases: (a) Foil strip loaded in its undeformed, straight state; and (b) foil strip loaded after being fitted into the bearing housing.

\section{Appendix D. Top Foil Matrices and Work Equivalent Load}

The top foil is modelled as two-node Euler-Bernoulli beam elements with rotational and lateral translation DOFs only. For an element of length $l_{t}^{e}$, Young's modulus $E_{t}$, depth $L$, thickness $t_{t}$, density $\rho_{t}$ and cross-sectional moment of inertia $I_{t}=\frac{1}{12} t_{t}^{3} L$, the stiffness and lumped mass matrices are given from [39] as

$$
\mathbf{K}_{t}^{e}=\frac{E_{t} I_{t}}{l_{t}^{e 3}}\left[\begin{array}{cccc}
12 & 6 l_{t}^{e} & -12 & 6 l_{t}^{e} \\
& 4 l_{t}^{e 2} & -6 l_{t}^{e} & 2 l_{t}^{e 2} \\
& & 12 & -6 l_{t}^{e} \\
& & & 4 l_{t}^{e 2}
\end{array}\right], \quad \mathbf{M}_{t}^{e}=\frac{\rho_{t} L t_{t} l_{t}^{e}}{24}\left[\begin{array}{cccc}
12 & 0 & 0 & 0 \\
& l_{t}^{e 2} & 0 & 0 \\
& & 12 & 0 \\
& & & l_{t}^{e 2}
\end{array}\right],
$$

where the elements below the diagonals are given from symmetry.

Based on the linear element shape functions, a laterally working tapered pressure can be shown to give the work equivalent nodal loads

$$
\mathbf{f}_{p}^{e}=\frac{l_{t}^{e} L}{60}\left\{\begin{array}{c}
21 p_{1}^{e}+9 p_{2}^{e} \\
l_{t}^{e}\left(2 p_{1}^{e}+3 p_{2}^{e}\right) \\
21 p_{1}^{e}+9 p_{2}^{e} \\
-l_{t}^{e}\left(2 p_{1}^{e}+3 p_{2}^{e}\right)
\end{array}\right\},
$$

where $p_{1}^{e}$ and $p_{2}^{e}$ are the pressure values at the element nodes, $l_{t}^{e}$ is the beam element length and $L$ is the beam element width (normal to the load direction).

\section{References}

[1] W. J. M. Rankine, On the centrifugal force of rotating shafts, The Engineer April 9th (1869) 249.

[2] O. Reynolds, On the theory of lubrication and its application to mr. beauchamp tower's experiments, including an experimental determination of the viscosity of olive oil, Philosophical Transactions of the Royal Society of London 177 (1886) 157-234.

[3] H. H. Jeffcott, The lateral vibration of loaded shafts in the neighbourhood of a whirling speed.- the effect of want of balance, The London, Edinburgh, and Dublin Philosophical Magazine and Journal of Science 37 (1919) 304-314.

[4] W. J. Harrison, The hydrodynamical theory of lubrication with special reference to air as a lubricant, Transactions of the Cambridge Philosophical Society 22 (1913) 39-54.

[5] J. W. Powell, A review of progress in gas lubrication, Review of Physics in Technology 1 (1970) 96-129. 
[6] G. L. Agrawal, Foil air/gas bearing technology - an overview, in: ASME 1997 International Gas Turbine and Aeroengine Congress and Exhibition, ASME, 1997, p. 347. doi:10.1115/97-GT-347.

[7] NASA, Creating a turbomachinery revolution: Research at Glenn enables an oil-free turbine engine, FS-2001-07-014-GRC, 2001.

[8] V. Castelli, J. T. McCabe, Transient dynamics of a tilting pad gas bearing system, Journal of Lubrication Technology 89 (1967) $499-508$.

[9] H. Heshmat, J. A. Walowit, O. Pinkus, Analysis of gas-lubricated foil journal bearings, Journal of Lubrication Technology 105 (1983) 647-655.

[10] J. P. Peng, M. Carpino, Calculation of stiffness and damping coefficients for elastically supported gas foil bearings, Journal of Tribology 115 (1993) 20-27.

[11] J. W. Lund, Calculation of stiffness and damping properties of gas bearings, Journal of Lubrication Technology 90 (1968) $793-803$.

[12] J. W. Lund, Review of the concept of dynamic coefficients for fluid film journal bearings, Journal of Tribology 109 (1987) $37-41$.

[13] R. Hoffmann, T. Pronobis, R. Liebich, The impact of modified corrugated bump structures on the rotor dynamic performance of gas foil bearings, in: ASME Turbo Expo 2014: Turbine Technical Conference and Exposition, volume 7B, International Gas Turbine Institute, 2014, p. V07BT32A012. doi:10.1115/GT2014-25636.

[14] I. Iordanoff, Analysis of an aerodynamic compliant foil thrust bearing: Method for a rapid design, Journal of Tribology 121 (1999) 816-822.

[15] T. H. Kim, L. S. Andres, Heavily loaded gas foil bearings: A model anchored to test data, Journal of Engineering for Gas Turbines and Power 130 (2008) 012504

[16] J. S. Larsen, I. F. Santos, Efficient solution of the non-linear reynolds equation for compressible fluid using the finite element method, Journal of the Brazilian Society of Mechanical Sciences and Engineering 37 (2014) 945-957.

[17] D. Kim, Parametric studies on static and dynamic performance of air foil bearings with different top foil geometries and bump stiffness distributions, Journal of Tribology 129 (2007) 354-364.

[18] T. H. Kim, L. San Andrés, Analysis of advanced gas foil bearings with piecewise linear elastic supports, Tribology International 40 (2007) 1239-1245.

[19] Y. B. Lee, T. H. Kim, C. H. Kim, N. S. Lee, D. H. Choi, Unbalance response of a super-critical rotor supported by foil bearings-comparison with test results, Tribology Transactions 47 (2004) 54-60.

[20] T. H. Kim, L. San Andrés, Limits for high-speed operation of gas foil bearings, Journal of Tribology 128 (2006) 670-673.

[21] P. Vleugels, T. Waumans, J. Peirs, F. Al-Bender, D. Reynaerts, High-speed bearings for micro gas turbines: stability analysis of foil bearings, Journal of Micromechanics and Microengineering 16 (2006) 282-289.

[22] P. Bonello, H. M. Pham, A receptance harmonic balance technique for the computation of the vibration of a whole aero-engine model with nonlinear bearings, Journal of Sound and Vibration 324 (2009) 221-242.

[23] J. S. Larsen, I. F. Santos, S. von Osmanski, Stability of rigid rotors supported by air foil bearings: Comparison of two fundamental approaches, Journal of Sound and Vibration 381 (2016) 179-191.

[24] G. Grau, I. Iordanoff, B. B. Said, Y. Berthier, An original definition of the profile of compliant foil journal gas bearings: Static and dynamic analysis, Tribology Transactions 47 (2004) 248-256.

[25] D.-H. Lee, Y.-C. Kim, K.-W. Kim, The dynamic performance analysis of foil journal bearings considering coulomb friction: Rotating unbalance response, Tribology Transactions 52 (2009) 146-156.

[26] S. Le Lez, M. Arghir, J. Frene, Nonlinear numerical prediction of gas foil bearing stability and unbalanced response, Journal of Engineering for Gas Turbines and Power 131 (2009) 012503.

[27] P. Bonello, H. M. Pham, The efficient computation of the nonlinear dynamic response of a foil-air bearing rotor system, Journal of Sound and Vibration 333 (2014) 3459-3478.

[28] P. Bonello, H. M. Pham, Nonlinear dynamic analysis of high speed oil-free turbomachinery with focus on stability and self-excited vibration, Transactions of the ASME, Journal of Tribology 136 (2014) 041705.

[29] J. S. Larsen, I. F. Santos, On the nonlinear steady-state response of rigid rotors supported by air foil bearings-theory and experiments, Journal of Sound and Vibration 346 (2015) 284-297.

[30] J. S. Larsen, B. B. Nielsen, I. Santos, On the numerical simulation of nonlinear transient behavior of compliant air foil bearings, in: Proceedings of the 11. International Conference on Schwingungen in Rotierenden Maschinen (SIRM2015), Magdeburg, Germany, 2015.

[31] S. Le Lez, M. Arghir, J. Frene, A new bump-type foil bearing structure analytical model, Journal of Engineering for Gas Turbines and Power 129 (2007) 1047-1057.

[32] L. San Andrés, T. H. Kim, Improvements to the analysis of gas foil bearings: Integration of top foil $1 \mathrm{~d}$ and $2 \mathrm{~d}$ structural models, in: ASME Turbo Expo 2007: Power for Land, Sea, and Air, volume 5, International Gas Turbine Institute, ASME, Montreal, Canada, 2007, pp. 779-789. doi:10.1115/GT2007-27249.

[33] N. Mostaghel, T. Davis, Representations of coulomb friction for dynamic analysis, Earthquake Engineering \& Structural Dynamics 26 (1997) 541-548.

[34] E. P. Petrov, D. J. Ewins, Generic friction models for time-domain vibration analysis of bladed discs, American Society of Mechanical Engineers, International Gas Turbine Institute, Turbo Expo (Publication) IGTI 4 (2003) 223-233.

[35] C. Makkar, W. E. Dixon, W. G. Sawyer, G. Hu, A new continuously differentiable friction model for control systems design, in: Proceedings of the 2005 IEEE/ASME International Conference on Advanced Intelligent Mechatronics, IEEE, Monterey, California, USA, 2005, pp. 600-605. doi:10.1109/AIM.2005.1511048.

[36] S. Le Lez, M. Arghir, J. Frene, A dynamic model for dissipative structures used in bump-type foil bearings, Tribology transactions 52 (2008) 36-46.

[37] J. S. Larsen, A. J. Hansen, I. F. Santos, Experimental and theoretical analysis of a rigid rotor supported by air foil bearings, Mechanics \& Industry 16 (2015) 106.

[38] B. J. Hamrock, Fundamentals of Fluid Film Lubrication, McGRAW-HILL Series in Mechanical Engineering, McGRAW-HILL, Inc., New York, 1994

[39] R. D. Cook, D. S. Malkus, M. E. Plesha, J. W. Witt, Concepts and Applications of Finite Element Analysis, 4 ed., John Wiley, New York, 2002 . 
[40] D. Ruscitto, J. McCormick, S. Gray, Hydrodynamic air lubricated compliant surface bearing for an automotive gas turbine engine. I. Journal bearing performance, Technical Report NASA CR-135368, NASA, 1978.

[41] Z. C. Peng, M. M. Khonsari, Hydrodynamic analysis of compliant foil bearings with compressible air flow, Journal of Tribology - Transactions of the Asme, 126 (2004) 542-546.

[42] L. San Andrés, T. H. Kim, Analysis of gas foil bearings integrating fe top foil models, Tribology International 42 (2009) 111-120.

[43] S. A. Howard, L. San Andrés, A new analysis tool assessment for rotordynamic modeling of gas foil bearings, Journal of Engineering for Gas Turbines and Power 133 (2011) 022505.

[44] F. A. Tariku, R. J. Rogers, Improved dynamic friction models for simulation of one-dimensional and two-dimensional stick-slip motion, Journal of Tribology - Transactions of the ASME 123 (2001) 661-669.

[45] J. S. Larsen, A. C. Varela, I. F. Santos, Numerical and experimental investigation of bump foil mechanical behaviour, Tribology International 74 (2014) 46-56.

[46] J. T. Oden, J. A. C. Martins, Models and computational methods for dynamic friction phenomena, Computer Methods in Applied Mechanics and Engineering 52 (1985) 527-634.

[47] J. A. Walowit, J. N. Anno, Modern developments in lubrication mechanics, Applied Science Publishers London, 1975.

[48] C. P. R. Ku, H. Heshmat, Compliant foil bearing structural stiffness analysis: Part i - theoretical model including strip and variable bump foil geometry, Transactions of the Asme Journal of Tribology 114 (1992) 394-400.

[49] U. M. Ascher, L. R. Petzold, Computer Methods for Ordinary Differential Equations and Differential-Algebraic Equations, Society for Industrial and Applied Mathematics, Philadelphia, PA, USA, 1998.

[50] M. Z. Poulsen, P. G. Thomsen, N. Houbak, Structural analysis of DAEs, Ph.D. thesis, Technical University of Denmark, Lyngby, Denmark, 2002.

[51] L. F. Shampine, M. W. Reichelt, J. A. Kierzenka, Solving index-1 daes in matlab and simulink, SIAM review 41 (1999) $538-552$.

[52] L. F. Shampine, Solving $0=f\left(t, y(t), y^{\prime}(t)\right)$ in matlab, Journal of Numerical Mathematics 10 (2002) 291-310.

[53] A. C. Hindmarsh, P. N. Brown, K. E. Grant, S. L. Lee, R. Serban, D. E. Shumaker, C. S. Woodward, Sundials: Suite of nonlinear and differential/algebraic equation solvers, ACM Transactions on Mathematical Software 31 (2005) 363-396.

[54] E. Hairer, G. Wanner, Solving Ordinary Differential Equations II: Stiff and Differential-Algebraic Problems, volume 14 of Springer Series in Computational Mathematics, 2 ed., Springer-Verlag, Berlin Heidelberg, 1996. doi:10.1007/978-3-642-05221-7.

[55] I. Santos, L. Molzen, On the experimental nonlinear modal analysis of a rigid rotor supported by air foil bearings, in: ASME Turbo Expo 2017 (submitted october 2016), ASME International Gas Turbine Institute, 2017.

[56] B. B. Nielsen, I. F. Santos, Transient and steady state behaviour of elasto-aerodynamic air foil bearings, considering bump foil compliance and top foil inertia and flexibility: A numerical investigation, Proceedings of the Institution of Mechanical Engineers, Part J: Journal of Engineering Tribology 2 (2017). 